\title{
Parametric Design and Daylighting: A Literature Review.
}

\author{
Ahmad Eltaweel, Yuehong SU \\ Department of Architecture and Build Environment, University of Nottingham, \\ Nottingham NG7 2RD, UK \\ Corresponding author: ahmad.eltaweel@nottingham.ac.uk, \\ yuehong.su@nottingham.ac.uk
}

\begin{abstract}
In the history, architecture was exploited to the human being to protect him from unsteady environmental conditions. In the past centuries, architecture was pioneer art which has special features such as; simplicity, organization, clear style, accurate decoration, material assembly, and so on. However, modern buildings become complex products that have so many parts which have to fulfil different functions. Therefore, new computational ways and techniques have been developed to facilitate the design of modern complicated buildings and to create a convenient quantitative relationship between the environment and the envelope, putting into consideration the obstacles which influence on the building design. This has therefore formed the concept of parametric design in architecture, in order to deal with complex designs and gain more accurate results. Modern architects claim that parametric design is the most creative way to understand the development and complexity of the new era of architectural trends [1]. Meanwhile, it is really hard to deal with sophisticated details in buildings using our brains to imagine, or conventional ways to design [2]. In addition, building technologies nowadays are integrated and containing many disciplines in the same time, and each discipline is dependent on the other disciplines in a very complex vast connections. Hence, they should be organized in a database container, and this container could be managed parametrically using parametric design as an advanced way to explore and understand these sophisticated relations [3]. This paper hence presents a literature review on parametric design in architecture practice and put a focus on its applications in daylighting and solar radiation, which can have an essential impact on improving daylight availability and energy saving.
\end{abstract}

\section{Keywords}

Parametric design; daylighting; solar radiation; energy saving. 


\section{Introduction}

In the general architectural design, all design aspects and their dimensions can be considered as parameters, such as location, orientation, shape, solar radiation and so on. In the conventional way of design, once an initial model has been created, and if the designer wants to change any parameter, the whole process has to be repeated, which is quite time-consuming. In contrast, the so-called parametric design employs a certain software such as Grasshopper to efficiently amend and improve design by integrating and coordinating design components simultaneously. Therefore, any change of parameters like editing or developing will be automatically and immediately updated in the model, which is like a "short cut" to the final model. A graphical comparison between the conventional approach and the parametric design is shown in Fig. 1.

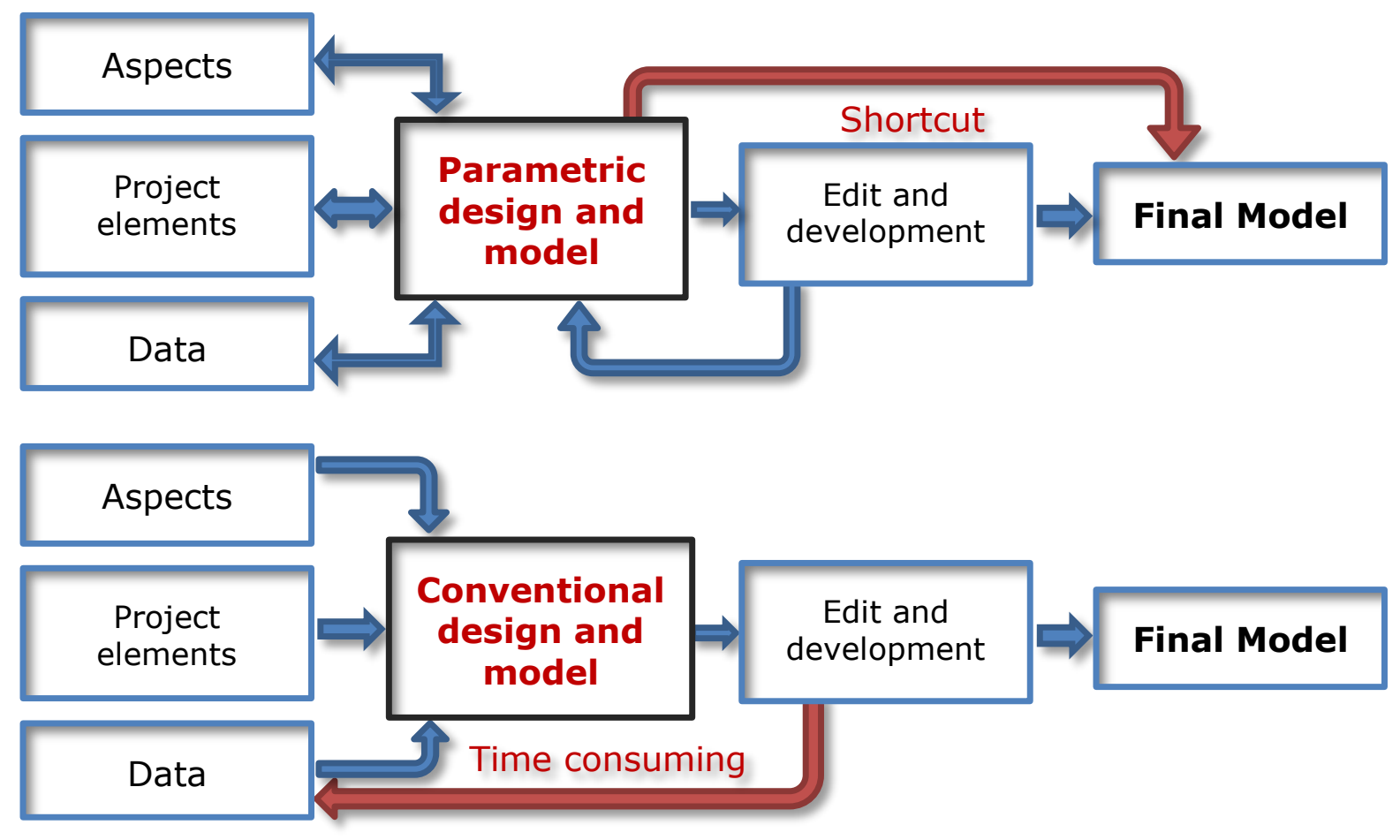

Fig. 1. Comparison diagram between Parametric design process, and conventional ones, showing the difference in time consuming.

Generally, the process of conventional design with a simple project is known for people as a design and coordinating process, where the idea of change, edit or develop is a usual process, and this process could be iterated till achieving the optimum design and best solution. However, for a company, this process will be more sophisticated according to different disciplines and project magnitude, in addition to the other design aspects. Accordingly, dealing with these complicated relations will be very difficult, complex, time-consuming and feasibility risky. Therefore, these complicated relations should be integrated using parametric methods. As mentioned in the previous diagram, parametric method can work with complex projects as a coordination tool, in order to facilitate the relation 
between different disciplines, moreover, dealing with modifications smoothly. These modifications will influence on the whole project disciplines with no need to iterate the whole project process [4], because, all parameters, disciplines and elements are connected parametrically.

\section{The origins of parametric term}

Daniel Davis, a researcher in the technology of the building industry, RMIT University, his PhD was about computational design; wrote a thesis about Parametric Origins titled as "A History of Parametric" [1]. According to his thesis, he claimed that the term parametric originates from mathematics, and the beginning of using this word is not known. Another researcher, David Gerber [5] claimed in his thesis Parametric Practices that Maurice Ruiter who is the first using this term in his book in 1988 which tilted as Advances in Computer Graphics III [6]. In the same year (1988) mathematician Professor Samuel Geisberg founded the PTC (Parametric Technology Corporation) [7] and created the first parametric modelling software called as Pro/ENGINEER, which is an integrated CAD/CAM/CAE solution, and was the first rule-based constraint applied software used nowadays in mechanical design in many companies [8]. In 1978, Hillyard and Braid [9] created a system which can combine between two parameters such as dimensions and tolerances in order to design a mechanical components, which could be considered as a parametric approach. On the other hand, Robert Stiles argued that the first appearance of parametric concept was earlier in the 1940 by Luigi Moretti in his book Writings of Architect [10] who wrote extensively about parametric architecture. However, Daniel [11] investigated in his thesis that there was also an earlier example; James Dana 1888 who was using the language of parameters, variables and ratios to define general steps to draw a range of crystals, which explained in his paper On the Drawing of Figures of Crystals [12].
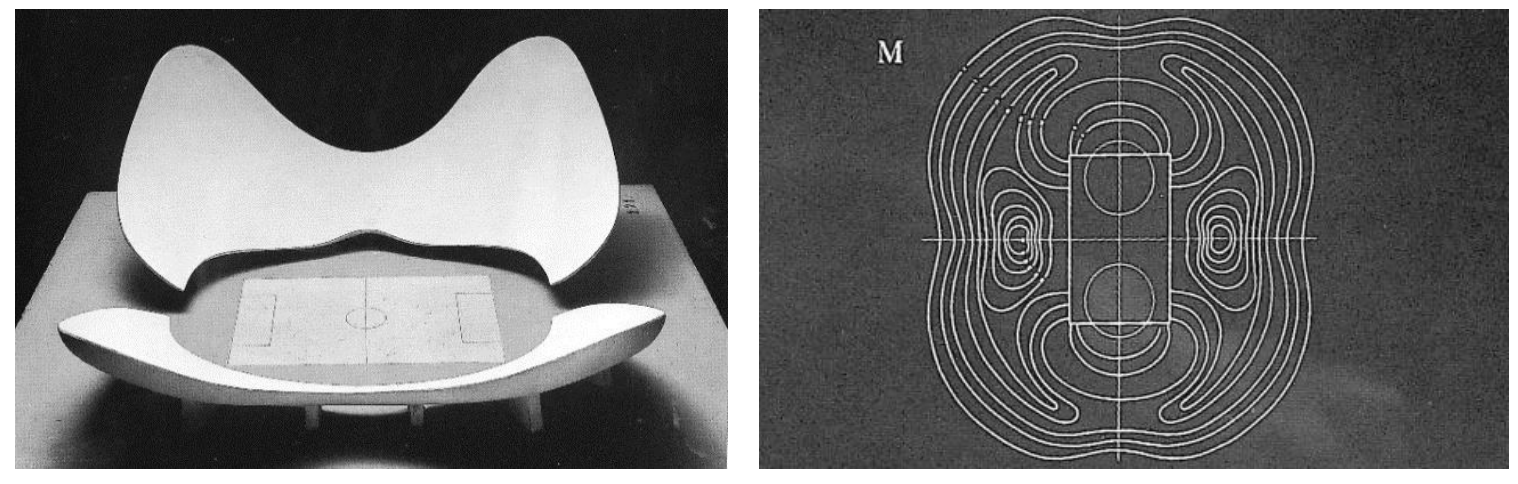

Fig. 2. A model of stadium by Luigi Moretti. Exhibited at the 1960 Parametric Architecture exhibition at the Twelfth Milan Triennial. The stadium derives from a parametric model consisting of nineteen parameters (left). The plans for the stadium (right) [10].

Moretti defined parametric architecture as the study of architecture systems aiming to "defining the relationships between the dimensions' dependent upon the various parameters". He used a stadium as an example to explain how the 
stadium's form can be divided into nineteen parameters, concerning things like viewing angles and economical cost of concrete as shown in Fig. 2. His parametric stadium was presented as part of his Parametric Architecture exhibition at the Twelfth Milan Triennial in $1960[1,11]$.

\section{The principle and implementation of parametric design}

Basically, the term parametric originates from mathematics, and refers to using certain parameters or variables, which can be amended in order to manipulate with the equation results [2]. Accordingly, the principle of parametric design can be defined as mathematical design, where the relationship between the design elements are shown as parameters which could be reformulated to generate complex geometries, these geometries are based on the elements' parameters, by changing these parameters; new shapes are created simultaneously.

For example, if we need to draw an integrated model consist of venetian blinds, and these blinds have specific rotation angles responding to sun movement. Accordingly, a mathematical equation should be created for these blinds in order to get the required rotation angle. Indeed, we have to substitute in the created equation every time the sun change its position, however, this process will be very long and time-consuming. In order to simplify this complex process; this mathematical equation can be gently done in a parametric formula using specific software, then the substitution will done automatically or in better words "parametrically". Accordingly, any changes in the data or parameters will influence on all the other parameters in the equation, which can appear in the final model, as shown in Fig. 3.

$$
\begin{gathered}
\delta=90-0.5(180-\alpha-\theta) \\
\theta=\tan ^{-1} u / v \\
\beta=\Omega-\delta
\end{gathered}
$$

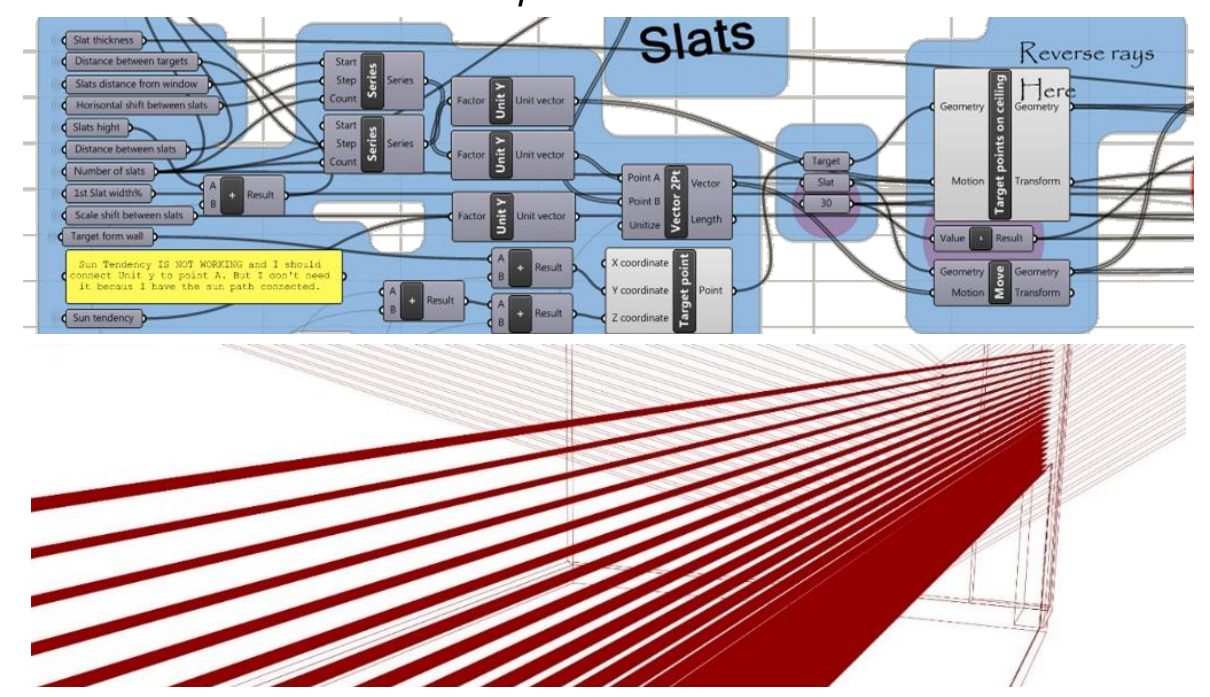

Fig. 3. The logical sequence of the modelling process; from the mathematical equation (top), which converted to the parametrical formula (middle), going to the final result of the model respectively (bottom). 
Where; $\delta$ is the opposing two angles over the slat, $\Omega$ is the solar profile angle, $\theta$ is the angle between reflected light and ceiling, $u$ is the distance from the Point $c$ to the Point $a, v$ is the distance from the Point $a$ to the target Point $b$, and $\beta$ is the slat tilt angle, see Fig. 4.

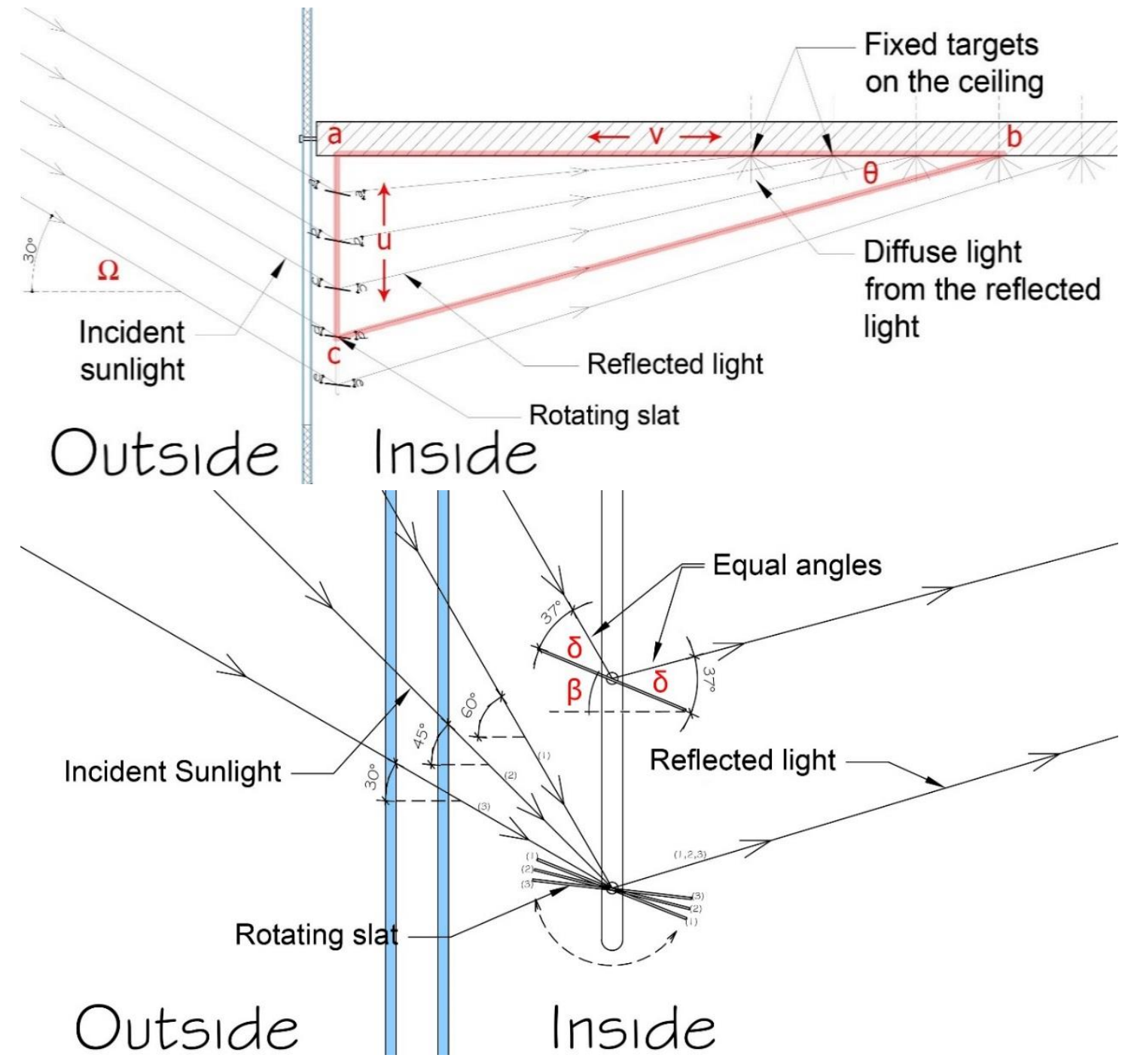

Fig. 4. Cross section in the model showing the used symbols in the equation (top), detailed cross section (bottom).

There are previous examples of using integrated modern systems in designing, such as Antoni Gaudi, who studied the design space using analogue models [2]. Recently, there are an obvious relation between parametric term and Computer Aided Design (CAD) systems [13], where CAD system facilitate the ways to draw a model based on geometrical relation with specified parameters and dimensions, however, if we need to edit or modify any element in the model; it will change only the parameters of this element independently regardless of other related elements. For example, if we need to change floor height of a building, we will modify the extrusion of the wall, meanwhile, other related parameters are needed to be modified as well - such as doors and windows - in order to match the room height. Accordingly, this process will be iterative and time consuming when dealing 
with complicated model. On the other hand, these modifications process can be performed simultaneously, by connecting the model elements with each other in an algorithmic relation known as "parametric design". Therefore, parametric design can be considered as an upgraded version of CAD system, while it depends on "Generative Algorithms" which is a way to explore design and algorithmic solutions through formulas rather than using normal geometries.

\section{Parametric design Software}

Parametric design software is a new tool revealed in 2008 and developed by many firms and software developers such as; Catia, 3D MAX, 3D Maya, Rivet, Grasshopper based on Rhinoceros 3D, Dynamo, GenerativeComponents, Marionette, and Modelur. However, the most common software used in this field is Grasshopper, while it is providing divergent plugins in many disciplines; such as architecture, urban planning, structural study, environmental analysis, mechanical engineering, sonic study, medicine, fashion, decoration and many other disciplines. For instance, "Ladybug" [14]a plugin in Grasshopper helps to create comprehensive information about the environmental state for any specific location by importing the standard EnergyPlus weather file (.epw) which can be obtained online from "https://energyplus.net/weather". In addition, these environmental information can be connected parametrically to the project data in order to understand the influence of weather and location on the studied project. Another example, "Honeybee" a plugin in Grasshopper as well, used as an engine to OpenStudio, Daysim, Radiance and EnergyPlus [14]while these programs are wellknown simulation tools and have vast utilities in daylight analysis, solar radiation, raytracing study, wind speed, humidity, heating and cooling energy consumption, etc [15]. All these plugins can be connected simultaneously and interact with each other, accordingly, more accurate and optimum results can be obtained. Although, Grasshopper can deal with many parameters simultaneously using low performance computer, however, it may take (2 5 minutes) longer - comparing to 3D MAX - in order to render a complicated model. On the other hand, Grasshopper in that case can provide an accurate and fast results comparing with other parametric design software such as Rivet and 3D MAX.

Generally, as mentioned previously Grasshopper is a graphical algorithm editor which serves as a parametric modelling linked to Rhinoceros 3D, that helps designers with no formal scripting background to easily generate parametric forms [16]. Parametric modelling refers to the automated parameter-based generation of any project elements. This means that the generation and alteration of the elements within a project is controlled with specific algorithm generated rule-sets. Elements are automatically drawn based on user-defined algorithms and by changing parameters within the algorithm; a design can be easily controlled [17]. Grasshopper thus provides full control and accurate manipulation of model's elements by defining form-generating components, which can be optimised 
through the use of sliders and mathematical expressions as shown in Fig. 3 (middle), or even with simple scripting. While, other software packages do not provide the necessary components for the creation of the work flow in as smooth and fluid manner as Rhinoceros and Grasshopper [16]. It can be noticed in Fig. 3 that Grasshopper interface consists of components or nodes known as capsules and they are connected as canvas in order to build the formula of Grasshopper, and this formula consists of different parameters. Changing these parameters causes the changes to the whole functions and geometries simultaneously, which can be observed in the Rhinoceros window.

Grasshopper has a significant characteristic in the optimization study; a component known as "Galapagos", is used to obtain the optimum results between multiple parameters based on the designer needs. Many researches used the method of optimization to find better solutions, such as Pratt and Bosworth [18] in order to get the best performance of a shaded window in their building.

\section{Implementations of parametric design}

Nowadays, parametric design is used in many fields, disciplines which consist of complex algorithmic relations, interdisciplinary work, creative forms, and multiprocessing treatments. It is not easy to control these operations using conventional tools or imagine them using our minds, so it is needed to use complex operating systems, parametric tools, and specific software. Due to this advancement in our life, we can find many implementations of parametric design in many fields like; decoration, fashion, architecture, urban planning, sonic study, structural analysis, medicine and so on.

\subsection{In urban planning}

Parametric design can provide several alternatives in a wide range of design, while it gives distinctive results in iterative design process, and these results can hardly obtained using conventional methods. The discrete method of problemsolving can deal with multiple layers in urban design case by saving time in writing formula and coordinating between these layers.

For example, the pedestrian pathway in a previous study [4] was chosen to determine the connections between the project's area, putting in consideration the smaller buildings which block the visual connection on streets. The sliced landscape was used to divide the pedestrian circulation into patterns. The formula created in this study conducted by Grasshopper was aiming to determine the shortest pedestrian pathway, as shown in Fig. $\mathbf{5}$. 

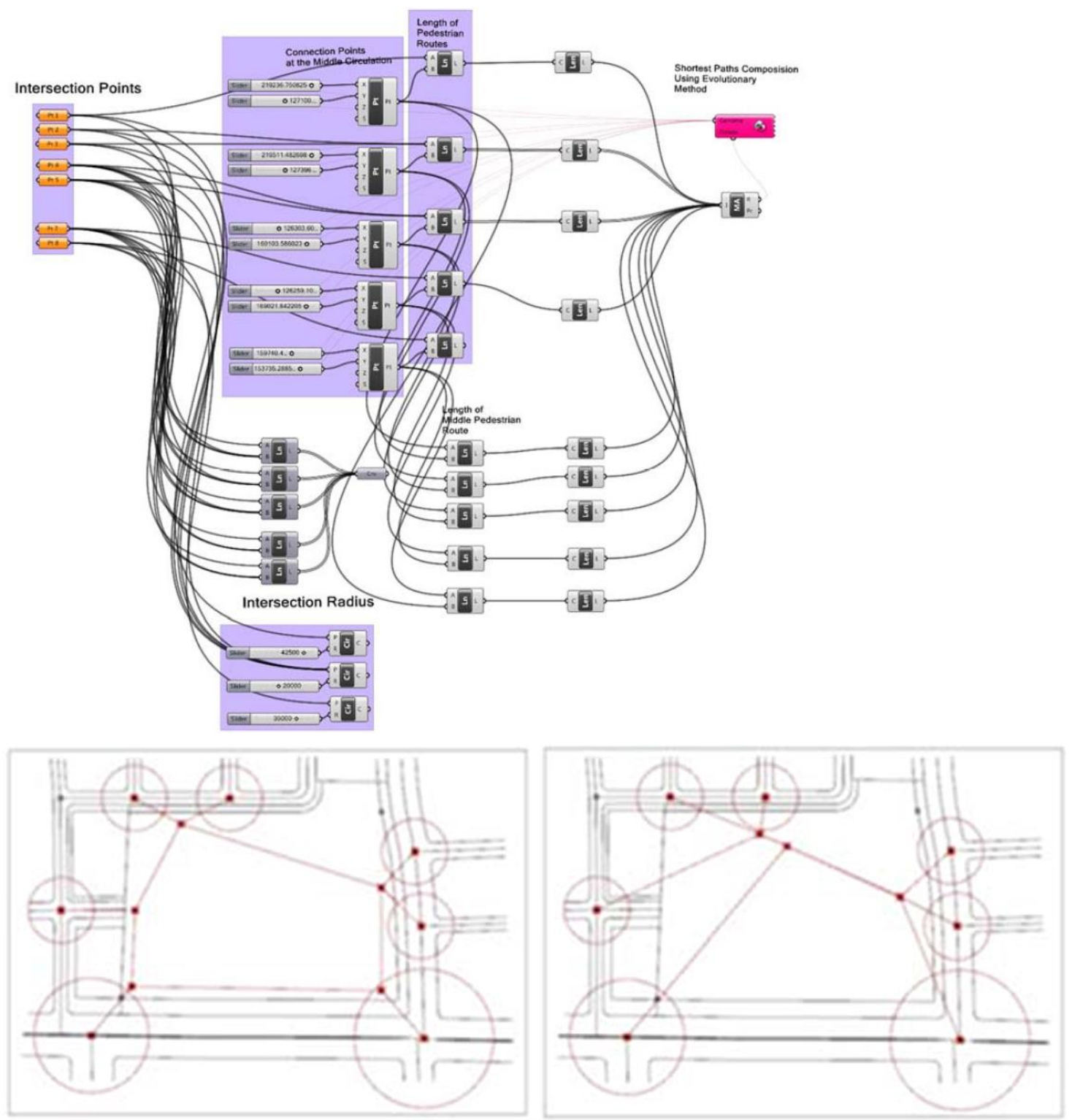

Fig. 5. The pedestrian formula in Grasshopper (top), the shortest solution for the pedestrian pathway (bottom) [4]

Another example in the same area, investigated by Mohamed and Khalid [19] in using parametrical methods to achieve more responsive environmental and sustainable urban morphology concerning human comfort values, such as wind study, solar envelop and daylight availability.

\subsection{In architecture}

Parametric design can generate creative solutions, deal with sophisticated relations and control them parametrically, and it utilizes parameters to set relations between design elements in order to define a range of formal alternatives. Moreover, parametric design provides wide exploration of multiple solutions to architectural design problems using algorithmic methods. Therefore, parametric design provides great opportunities to utopian architect to generate creative solutions in the design process $[20,21]$, see Fig. 6. 


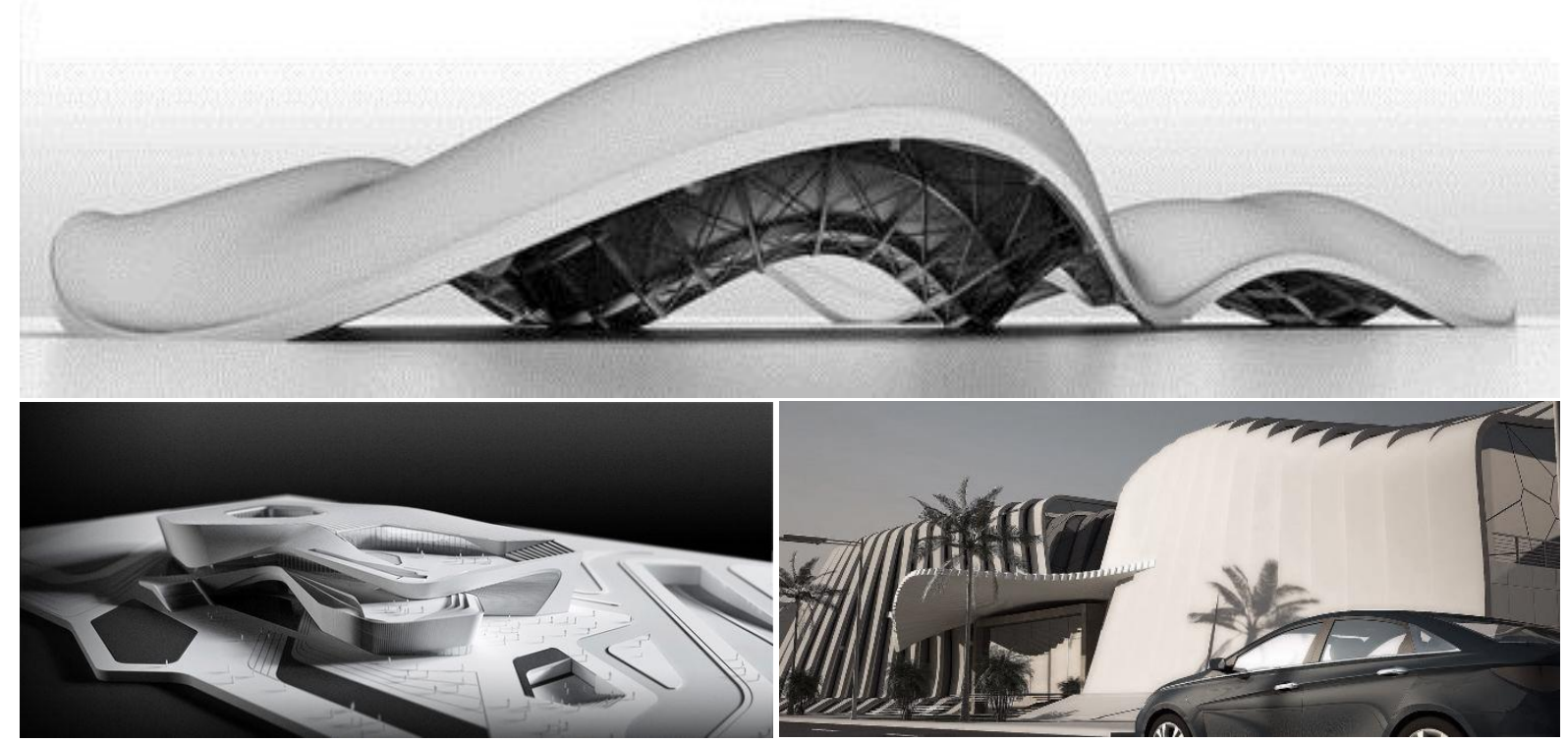

Fig. 6. Architectural models created based on parametric design [22], (bottom right designed by Ahmad Eltaweel).

\subsection{In decoration:}

Parametric design provides creative forms, iterative dynamic shapes which is inspired from the nature, and depends on algorithmic relations and connections. Moreover, it can create unlimited options of modular forms based on simple element, via adding parametric modifiers, see Fig. 7.
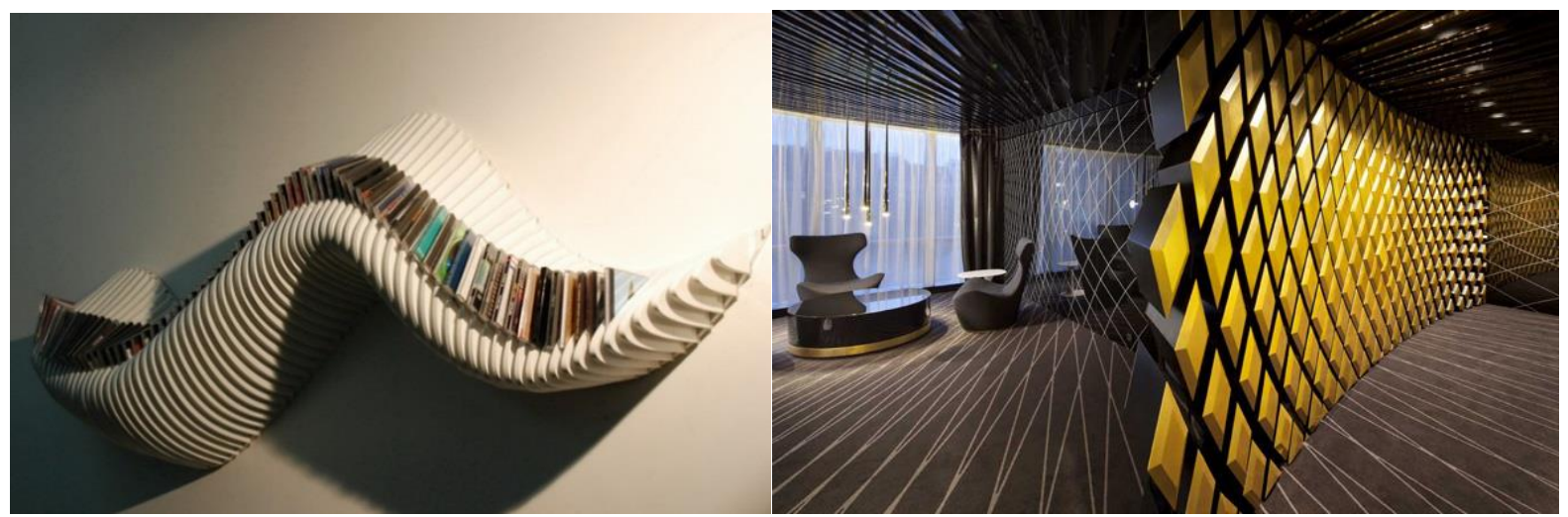

Fig. 7. Ideas of parametric design in decoration [23].

\subsection{In fashion:}

Nowadays paremetric design is used in wide range of design fields, becase it provids new unpredectable idesas with a future styles as shown in Fig. 8. 

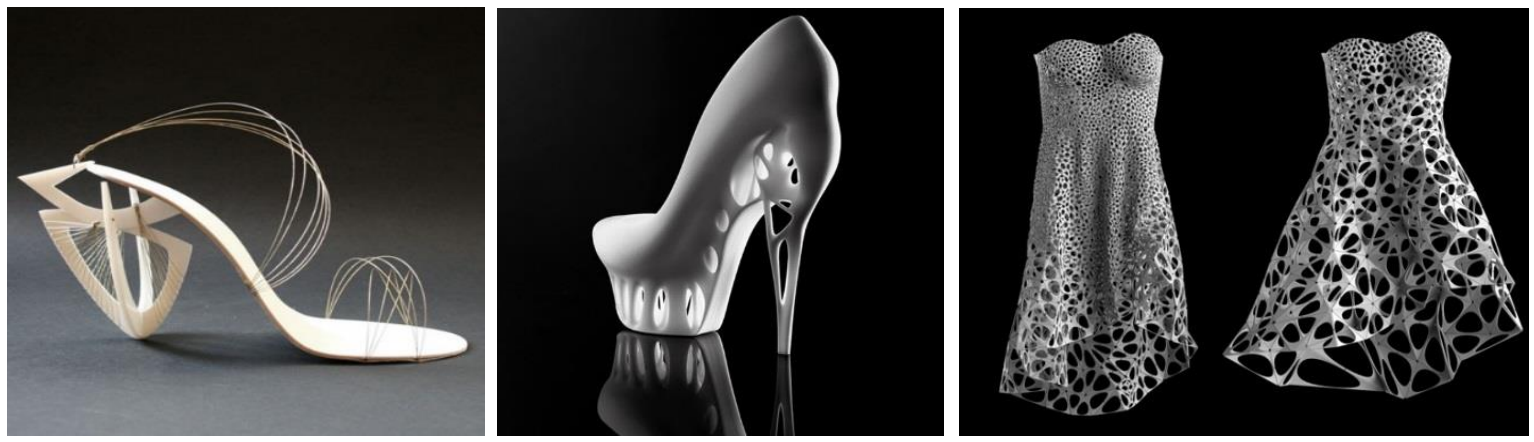

Fig. 8. Ideas of parametric design in fashion, inspired from nature [24-26].

\subsection{In sonic study:}

Parametric programs can be used in sonic studies to calculate reflections (bounces), cast multiple rays, calculate flow paths down a sloped surface like water runoff [27].

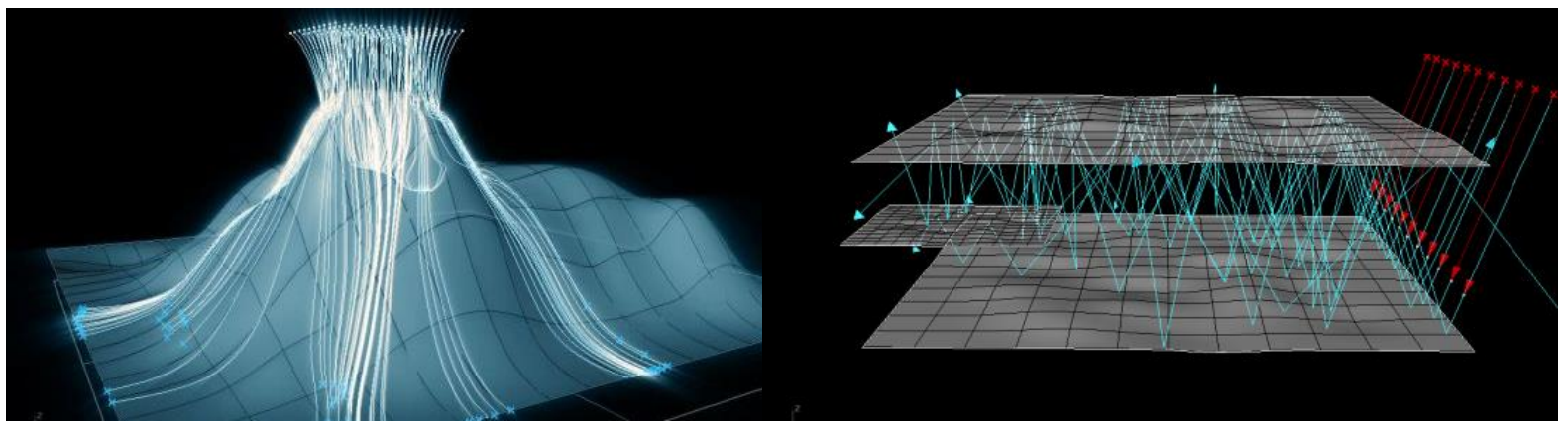

Fig. 9. Reflected rays calculated in "Sonic", a plugin based on Grasshopper [27].

\subsection{In structure study,}

Parametric design can calculate algorithmic formulas and manipulate complex connections, and create sophisticated relations with many kinds of materials as shown in Fig. 10.

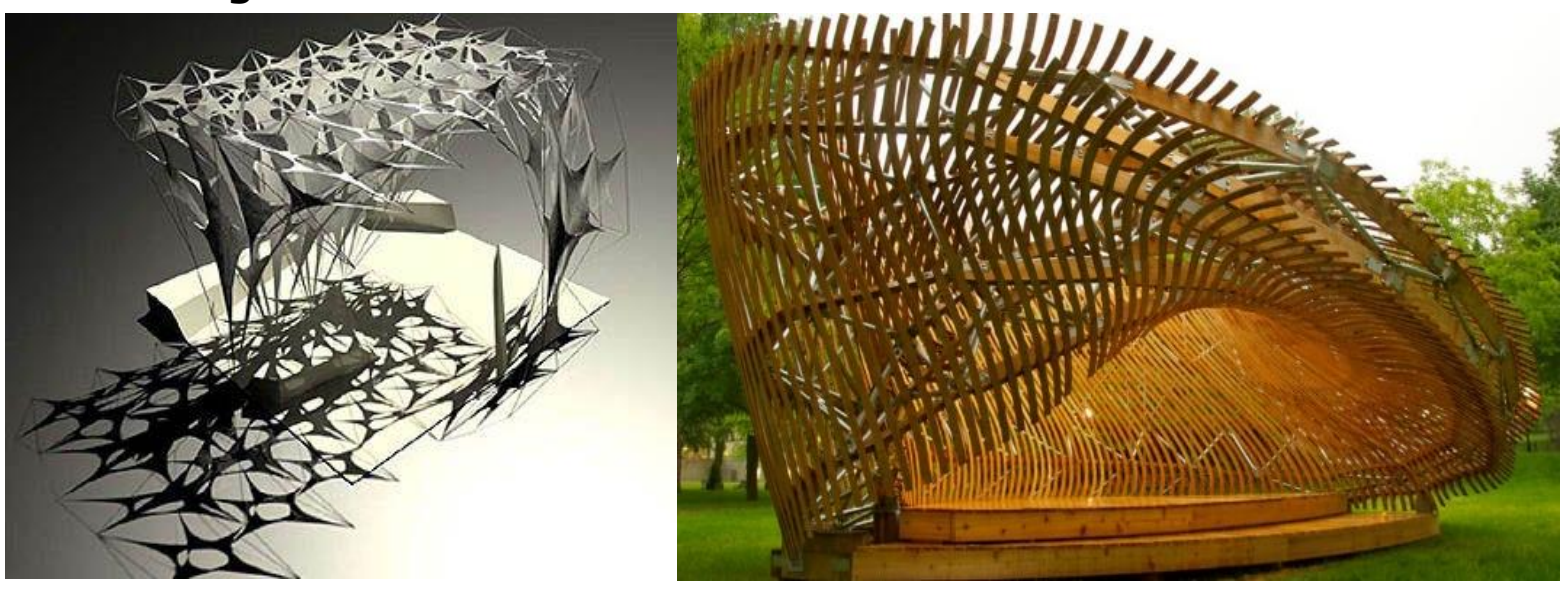

Fig. 10. Structure study using algorithmic calculations in Grasshopper [28, 29].

An example of a spiral building was investigated in a previous research [4] to study the structural system design. Diagrid system was chosen for this building 
according to the advantages of this shape [30]. The parametric method was applied to this building to specify deflections and material behaviour. This study done by analysing the algorithm, which concluded that spiral columns are no longer needed, and beam profiles can be smaller than standard ones, additionally,

they can be replaced by spring beam system, see Fig. 11.
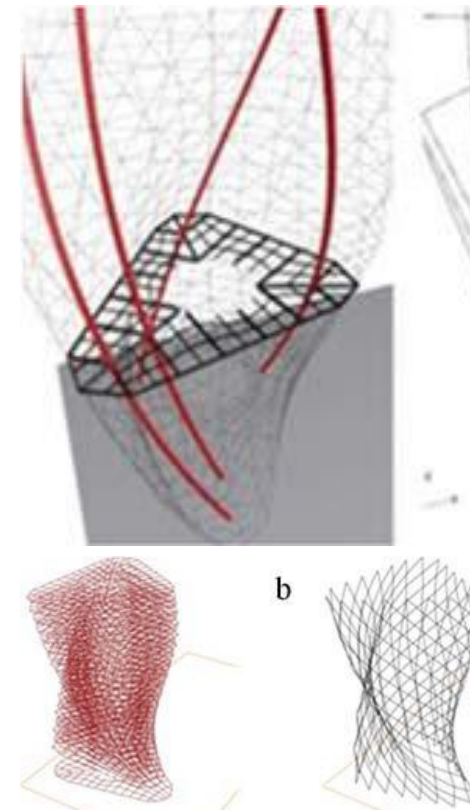

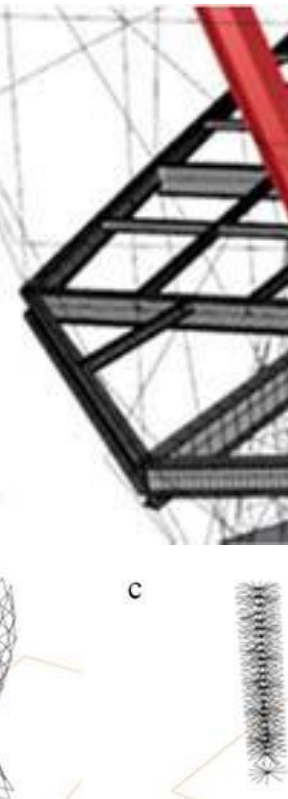

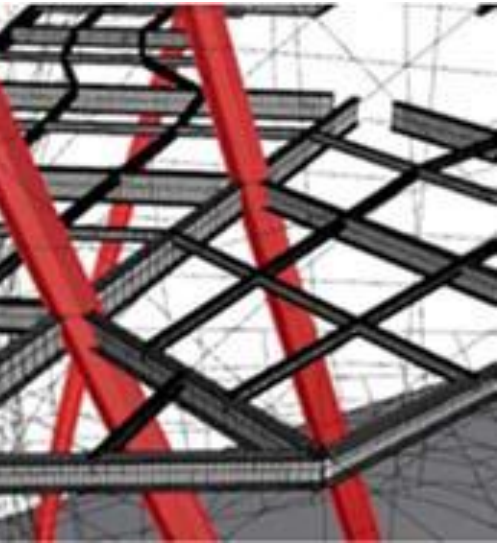

d

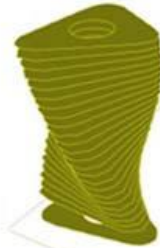

Fig. 11. Structural design analysis [4].

\subsection{In environmental study:}

Parametric programs can study and analyse all climatic and environmental changes such as sun movement, date, location, intensity, humidity, illumination, radiation, wind speed, heat gain, shadows, shades, and control them parametrically. In addition, it can make simulation in the $4^{\text {th }}$ dimension using the time aspect which can influence on the building in the real time, and how the time can change the performance of the building parametrically. So we can anticipate and solve many design issues the early stages of design [31-33].

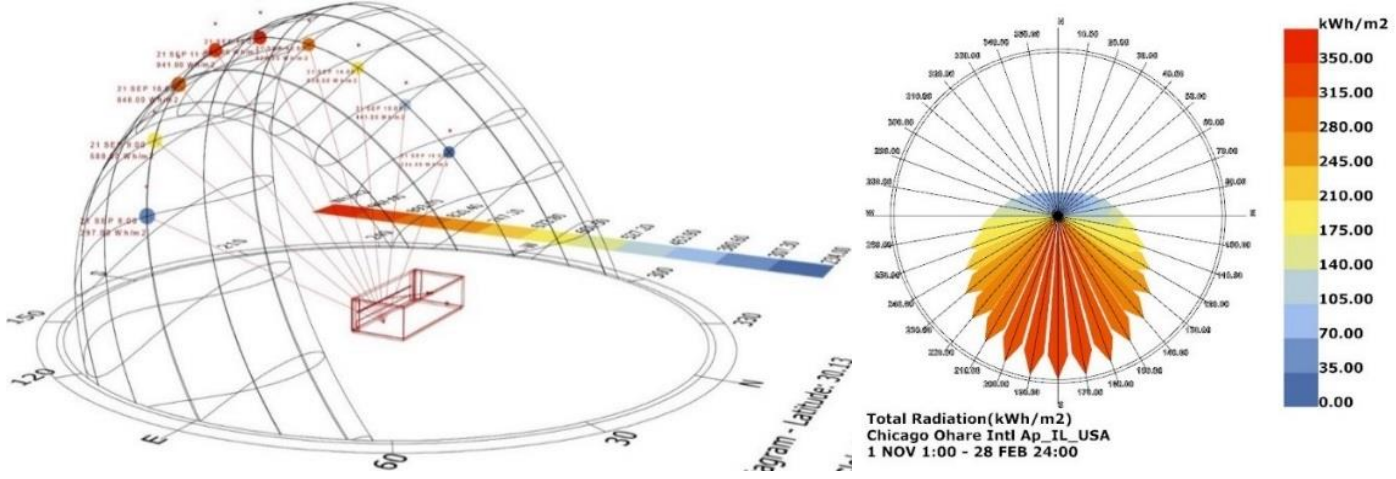

Fig. 12. Examples for sun path and daylight analysis, form our work in Grasshopper. 


\section{Parametric design and daylighting}

As mentioned before, parametric design can be utilized to solve and manipulate complex relations based on data availability, and these data are connected and depending on each other. Consequently any change on a given parameter will influence on the whole data.

In this literature review, daylight will be investigated with the utilization of parametric design. Daylight is an important aspect in our life, especially with the architectural decisions, such as design concepts, facades, forms, functions, orientation and even materials. Daylight influenced by many divergent criteria such as longitude, latitude, sun-path, solstice, equinox, sky type, wind speed, solar radiation, humidity and territory. All these aspects have different parameters and influenced by each other. Therefore, parametric design can provide this utility by connecting these data together using specific software, which can ease the design decision, modelling, and solving problems. Furthermore, it could anticipate the optimum solutions for the building design especially via analysing the influence of daylight.

\subsection{Louvers design}

Louvers design was investigated in a previous research [31] using parametric approach by exploring all possible screen configurations in daylighting. The method was done by using a parallel computing algorithm that allowed a better understanding of the effect of the louvers parameter and their interaction on daylighting performance. These parameters consists of louvers count, louvers depth ratio, tilt angle, window to wall ratio and reflectively, which were connected parametrically to give 1600 items, and they are divided to 200 groups, see Fig. 13 and Fig. 14. The process was working in a parallel simulation, and the simulation process was conducted by linking Grasshopper with Radiance through a particular algorithm known as Diva which was used to open Radiance and EnergyPlus interface engines [34].

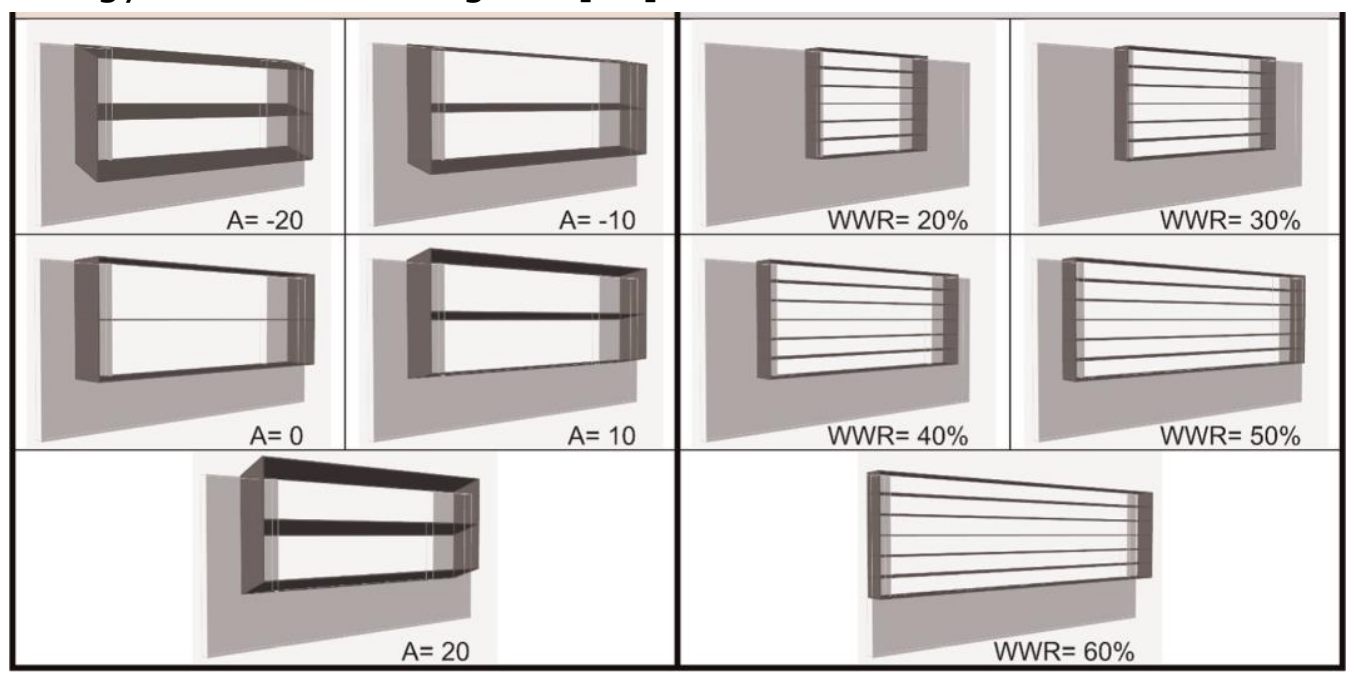

Fig. 13. The louvers' parameters [31], A: screen tilt angle, WWR: window to wall ratio. 
The study summarized that, increasing the louvers count from 3 to 10 leads to decrease of sDA (spatial Daylight Autonomy) from $40 \%$ to $30 \%$ respectively, at $30 \%$ WWR with 1.5 depth ratio. However, the sDA decreased form $76 \%$ to $61 \%$ at $50 \%$ WWR with the same depth ratio. However, when increasing the depth ratio from 0.75 to 1.5 with $20 \%$ WWR, the sDA decreased by $40 \%$, but this decline diminished as WWR increased till it disappeared at 60\% WWR where sDA reached the highest value of $100 \%$. In general louvers count was found that they have no remarkable influence on the SDA with relevant to the louvers depth ratio, which relatively have more impact on the SDA.

The utility of this study is that all parameters were explored in all screens, thus the evaluation of the experiment was effective, and the classification for the parameters was accurate via identifying the optimum solution. However, the disadvantage of studying many parameters together did not achieve an accurate results for the overall performance, so it would be better to study each parameter individually while fixing the others.

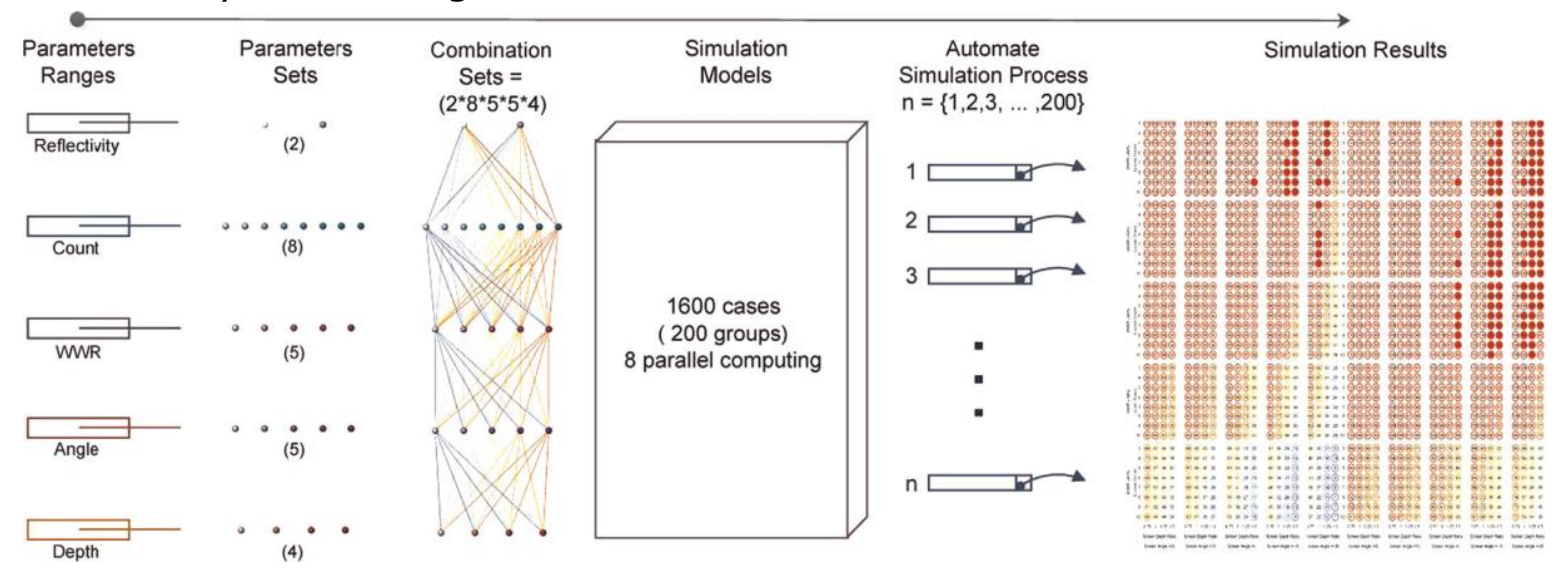

Fig. 14. Parametric algorithm for computing all possible combinations [31].

El Sheikh and Gerber [35] also investigated in louvers, through studying the design of intelligent building skin and its impact on daylighting performance, using parametric approach. The method of this study is done by using Grasshopper, Rhino, Diva and Galapagos as parametric tools to control and design exploration of semi-autonomous and fully autonomous configurations of an exterior building envelop louver system. The system was created to respond to the daylighting conditions and occupants' performance. The study summarized that daylighting performance was improved in the interior spaces putting in consideration the occupants' preferences and building's requirements, and the research proves that using the automation of independent tilt angles can improve the Building Intelligent Skin system to two times better than conventional system, concerning daylight harvesting.

Sjarifudin and Justina [36] as well investigated in automated louvers by using new kind of design method called parametric camshaft. The method of this study is done by simulating a workspace in Jakarta with variation of shading angles aiming to provide sufficient daylight inside the workspace. The study summarized 
that the occupants' visual comfort can be achieved by varying the shading opening angles between $15-75^{\circ}$. However, Jaepil, Taekyoung, Euisoon and Gensong [37] used parametric louvers in their study to optimize the thermal performance in the building, by analysing the best adjustment for the louvers. The study investigated in the louvers' performance from three aspects; the distance from glazing, the louver's depth and the louver's tilt angle. The simulation of this study was conducting using Rhinoceros, Grasshopper, Ecotect, and Galapagos.

In a former literature review, Maria and Aris [38] investigated in dynamic and automated shading systems, using sensor points and controlled algorithms which responding to the sun movement and weather conditions. The review concluded that the most popular automated systems and motorized Venetian blinds can achieved $20 \%$ and $50 \%$ in energy saving for cooling and lighting respectively, comparing to conventional louvers.

\subsection{Skylight design}

A research investigated in responsive skylight system by Goncalo, Jose and Vitor [33] which aims to create a skylight system that responds to environmental conditions and internal functional demands. The system uses three aspects; location, time and sky conditions. This paper studied the process to control daylight dynamically, using a Tetra-Script pavilion prototype, which targets to provide adequate illumination and low visual contrast. The experiment was conducted parametrically using an environmental software analysis to generate a criteria to evaluate the results. The model was responding to the sun in a Heliotropic response, which is a natural phenomenon of some species of plants that follows the sun movement in order to receive more sunlight, such as the snow buttercup. The automation process of this experiment was done parametrically using Grasshopper, and the configuration of the pavilion is determined by a small set of variables including basic form, tessellation and texture were the static adaption, and the aperture degrees of the skylight panels adopted automatically [39], see Fig. 15 and Fig. 16.

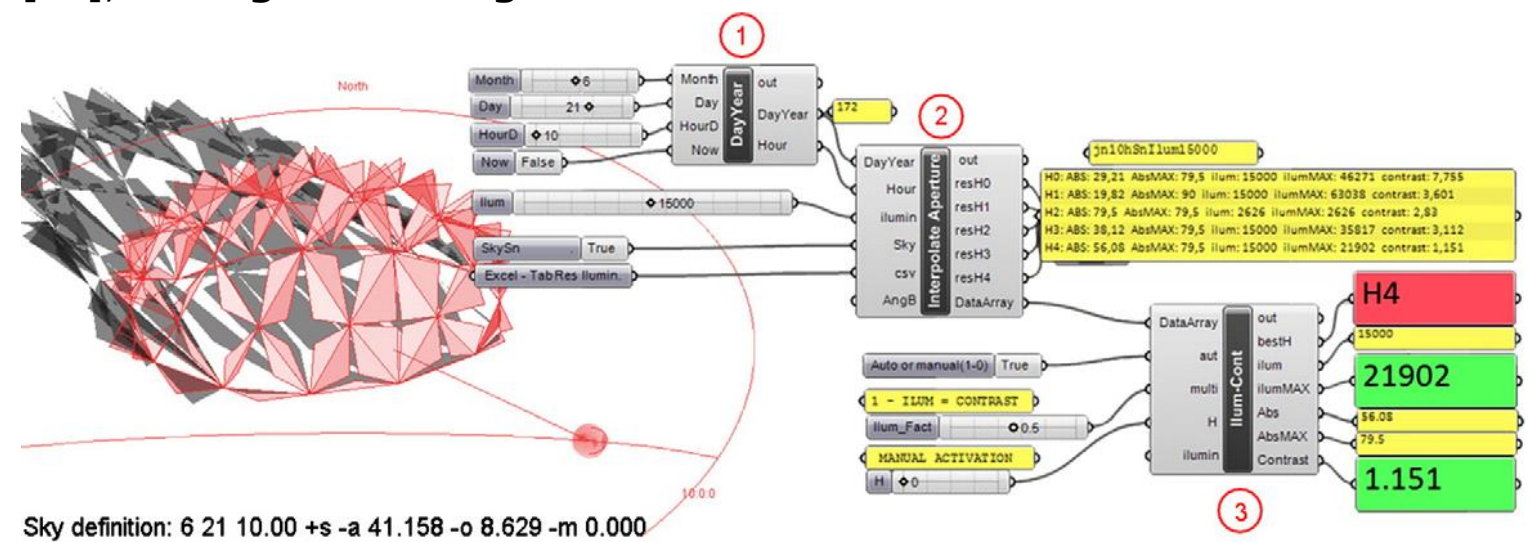

Fig. 15. The controlling process using Grasshopper [33]. 


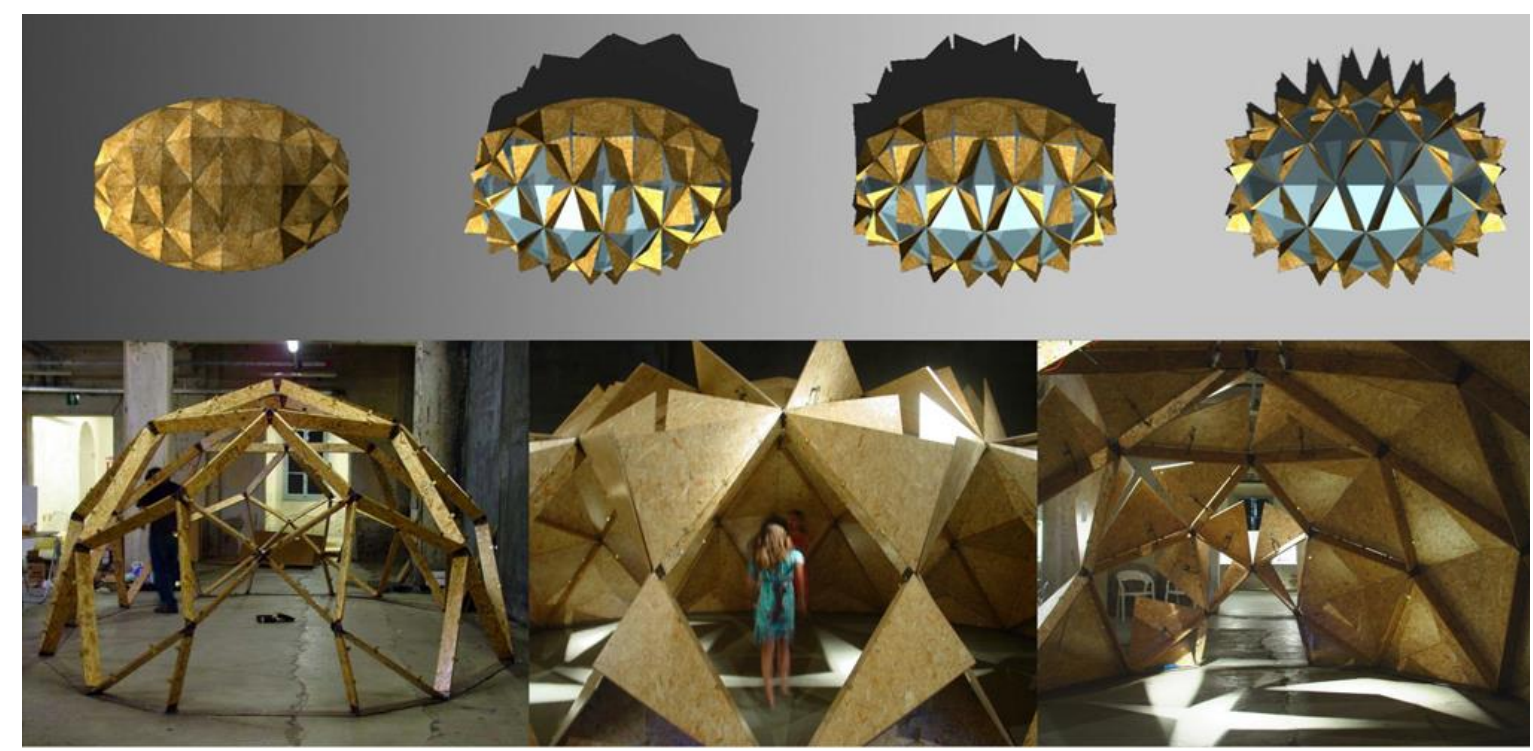

Fig. 16. The TetraScript pavilion concept, controlled parametrically [33].

Results calculated using interpolation method showing an approximate illuminance error between $4.3 \%$ and $7.3 \%$, however, the detailed results of this research are described in the author's PhD thesis. The parametric design system used for the generation of skylight configurations, can be applied to any pavilion shapes, with other geometries, at any location. The advantage of responsive system, that the configurations of daylight performance can be set in real-time.

The whole results of the study including daylighting simulation, heuristics, apertures values, and the best-case worst-case situations were stored in a data base. This data base can be used to determine the apertures of the skylights that provide required illuminance, and resulting visual contrast value.

A further research in the same issue made by Michela, Peter, Axel and Rudi [40] who also investigated in the performance-oriented design of large roof structure for semi-outdoor space aiming to enhance the environmental performance of the space in the early stages of the design process, moreover, studying passive solar strategies that reduce the need of imported energy via analysing the daylight and thermal comfort. The study uses parametric geometry to generate design alternatives, and the exploration performance was studied using a parametric tool called ParaGen which is a plugin connected to Grasshopper that studying structural systems and their form performance criteria using genetic algorithms [41], see Fig. 17.

The research described that in order to achieve passive strategies for thermal comfort; the temperature should be decided by the physics of the form instead of building engineer, moreover, the location of its mass, size, orientation of the openings, and shading in order to achieve zero-energy space [42].

The study found that the lowest ratio between the yearly incident solar radiation and daylight factor was about 3.5 times smaller than the highest ratio. Accordingly, this software was utilised to create the model parametrically to search for the optimum openings settings, and better energy related aspect, which 
resulted a successful potentials based on the case study. The study summarized that parametric design approach can provide full control to deal with complex geometries, which offers a highly visual interface as well as wide variety of different scripts, in addition, increase the versatility of the design process, which gives further variations of the geometric models.

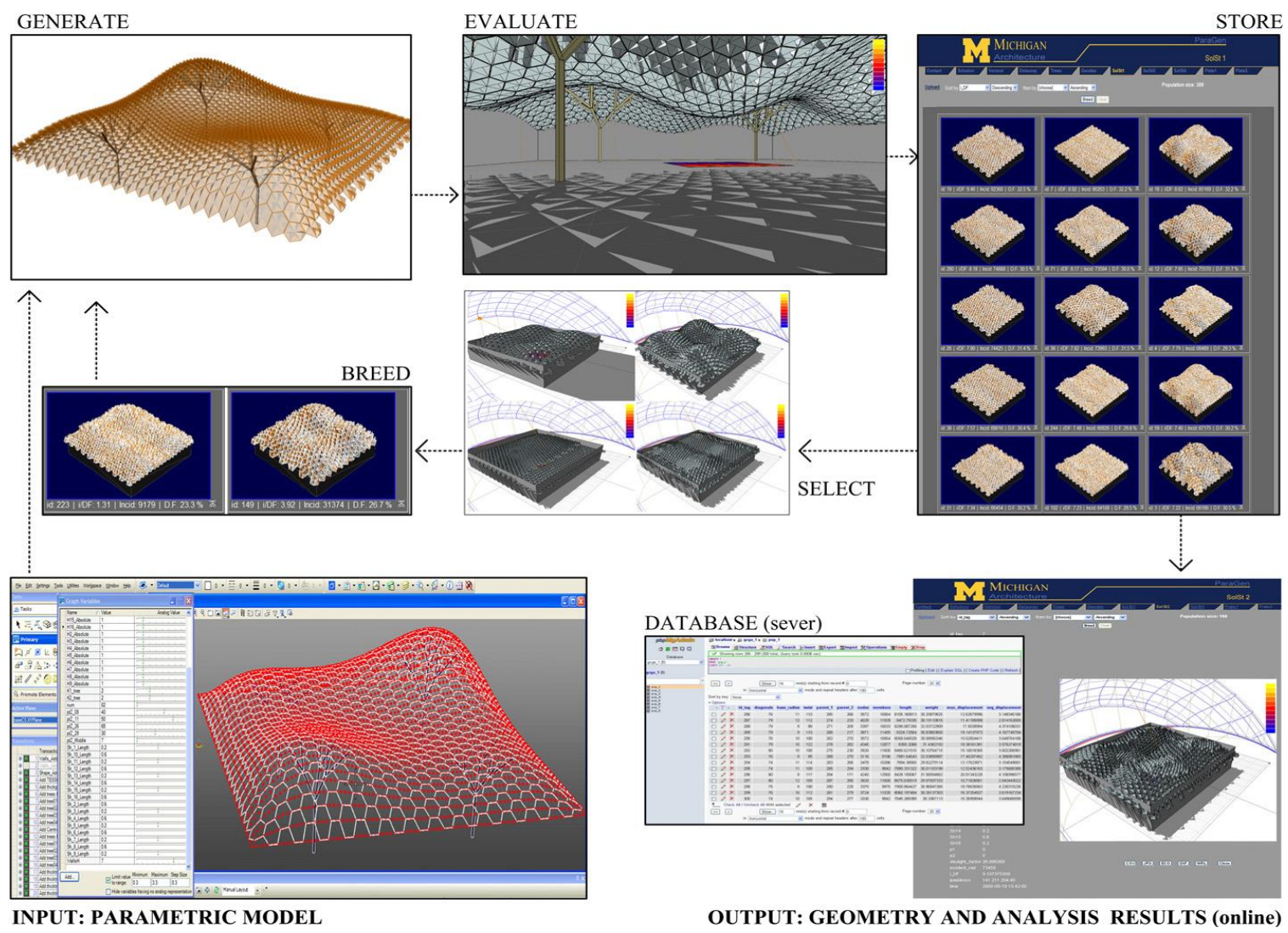

Fig. 17. The ParaGen cycle [40].

In the same issue, M. Turrin, E. Van, A.Kilian and S.Sariyildiz [43] investigated in using parametric design to improve the performance of a large span roof in Bologna. The study aims to exploit the use of renewable resources in the site by reducing the summer overheating, enhance the daylight and provide a good ventilation to the project. Parametric design here was occupied to manipulate with the structural morphology of the building by controlling the apertures based on variation of size and distribution, in order to meet the requirements of passive building. The 3D geometry of the structural roof consists of ETFE pneumatic modules, which is controlled by a moveable layer adjusted to three positions, where the closed position provides an opaque state, and the open position can allow the light to penetrate between the patterns.

The study found that in order to achieve the best balance between a low solar factor and a high daylight transmission; the apertures opening angles should be between 60 and 70 degrees, which resulting approximately $30 \%$ of solar energy transmission (G-value) which was the best measured value to improve thermal comfort in summer. 
Patric, Paul, and Kera [44] suggested multiple designs of an atrium at University of Massachusetts in Lowell in order to lit the building floors and bring daylight deep in to buildings spaces. They used parametric approach in design process such as Diva for Rhino and Grasshopper. The methodology of the study depends on using reflective systems to exploit the daylight and bring the light into the building's interior surfaces, by analysing many systems techniques used in different buildings as shown in Fig. 18.

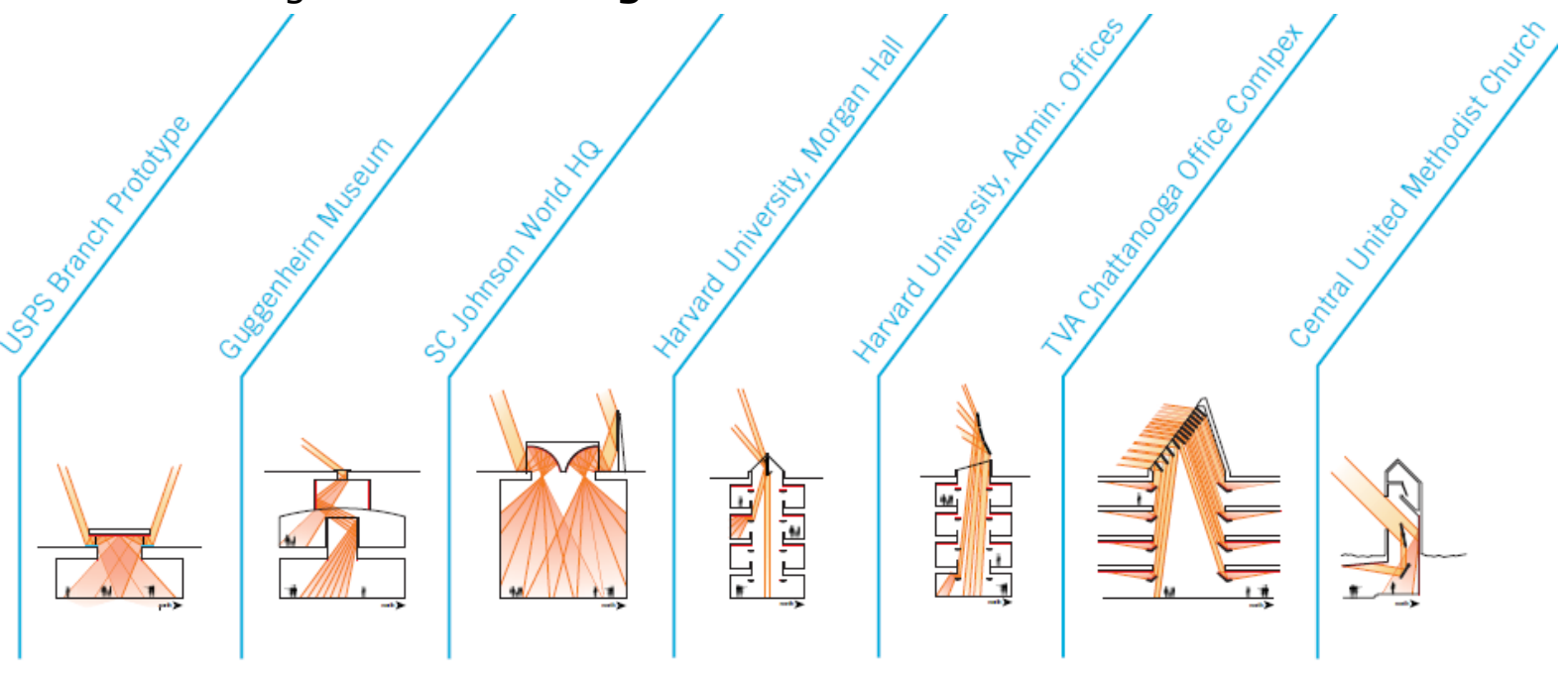

Fig. 18. Different types of reflective system design [44].

The reflective systems used in this study is a pairing of two main daylighting techniques; the first is a large north facing window as a source of diffuse light, and the second is a south facing mirrored reflector hung within inside the atrium skylight as shown in Fig. 19.
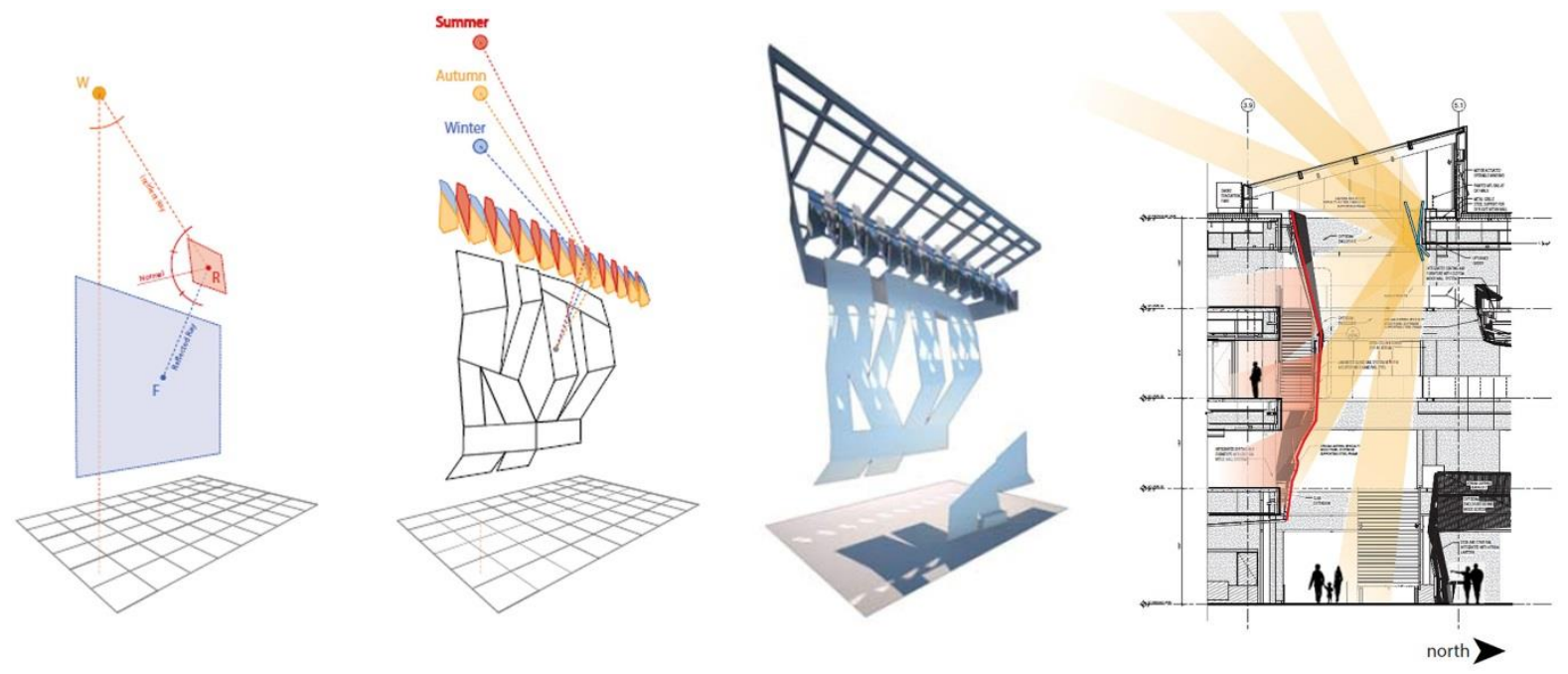

Fig. 19. Daylighting redirecting strategies at University Crossing [44].

Jong and Bharat [45] proposed an innovative technique to light a gymnasium hall in Korea, which is parametrically bio-inspired by superposition compounds eyes of animals $[46,47]$ which can absorb wide range of light better than normal eyes. The system consists of reflecting superposition optics which can capture and 
distribute daylight inside the building dome structure, furthermore, it can respond to the sun movement. The proposed biomimetic model was designed parametrically via using Rhinoceros and Grasshopper. The roof surface of the gymnasium is subdivided to cuboid structure that was formed as a tapered rectangular prism. Each façade component inside the cube can adjust itself to respond to the sun movement, by shifting the bottom of the components to meet the functional requirements based on climatic state, see Fig. 20.
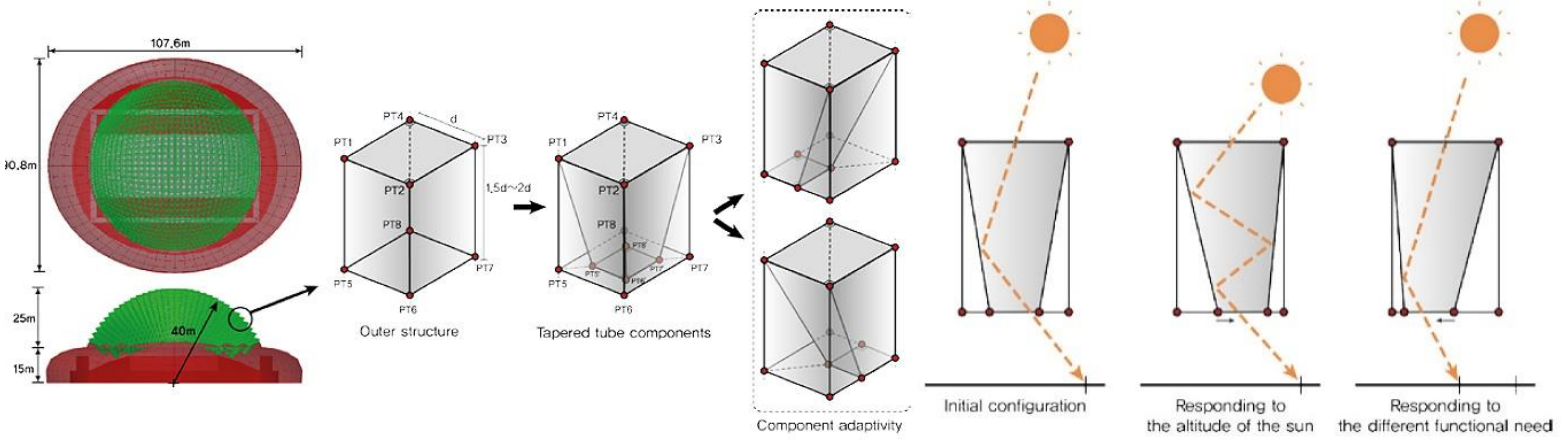

Fig. 20. Configuration of adaptive façade components.

The Kinetic mechanism of this system can adapt itself corresponding to two different objectives; firstly, keeping the playing area illuminated responding to different sun positions, and secondly, changing illuminance conditions for the needed functional purposes. The study summarized that parametric design tools provides wide design explorations, and opens more opportunities for innovative building systems to adapt on their own to environmental changes and to become more passively energy-efficient via exploiting natural resources. However, in order to perform perfectly, the system still need high number of sensors to respond to the environmental changes, in addition, the complexity of elector-mechanical, and maintenance cost.

\subsection{Mass and shadow study}

William, Aswin and Heru [4] used parametric approach in their study as a tool to solve problems during design process regarding to site planning and massing. The study was conducted on office tower in Jakarta. The study aimed to evaluate the feasibility of using parametric design method. Therefore, the method being employed in this study to solve each problem individually, by creating a formula in Grasshopper containing all data with a specific parameter.

The shadows were investigated in this study by analysing the neighbouring buildings that overshadow the site, which was utilized by the sun-path diagram to create a trace of building's shadow at a specific hours, see Fig. 21. 

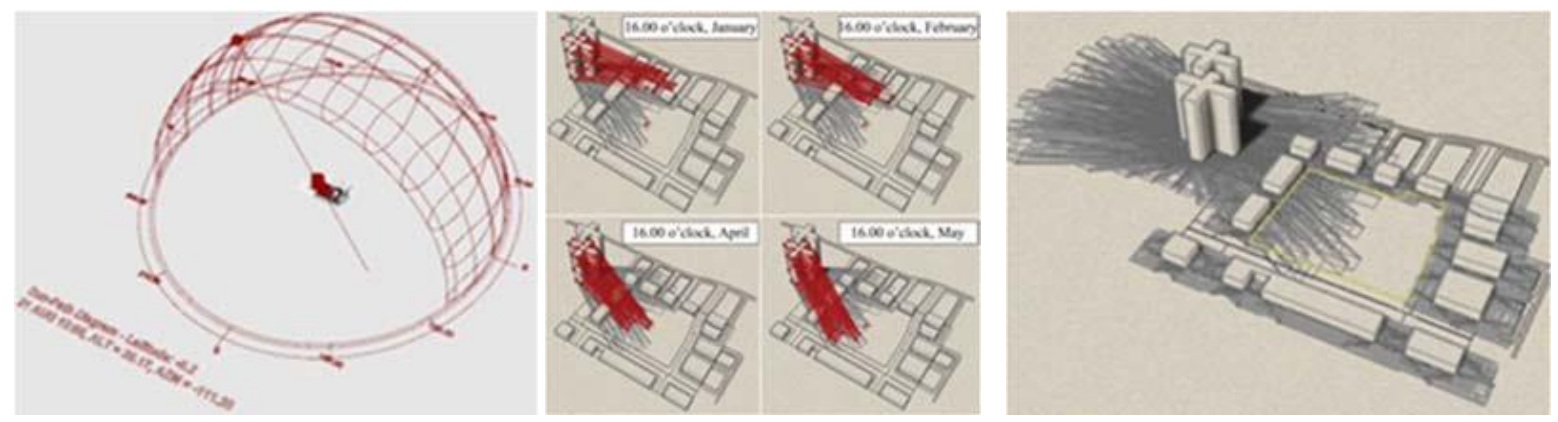

Fig. 21. Overshadow of neighbouring buildings [4].

The overshadow study concluded that, the western part of the site would be more comfortable in the afternoon as it is overshadowed by surrounding buildings after 3pm, from February to October. Likewise, in Fig. 22 searching for the most comfortable area along the year, while this overshadowed area will be allocated for public spaces for human activities. The utility of parametric design in this condition is the ease of controlling sun location which can be iterated during daytime based on specific location imported from weather file.
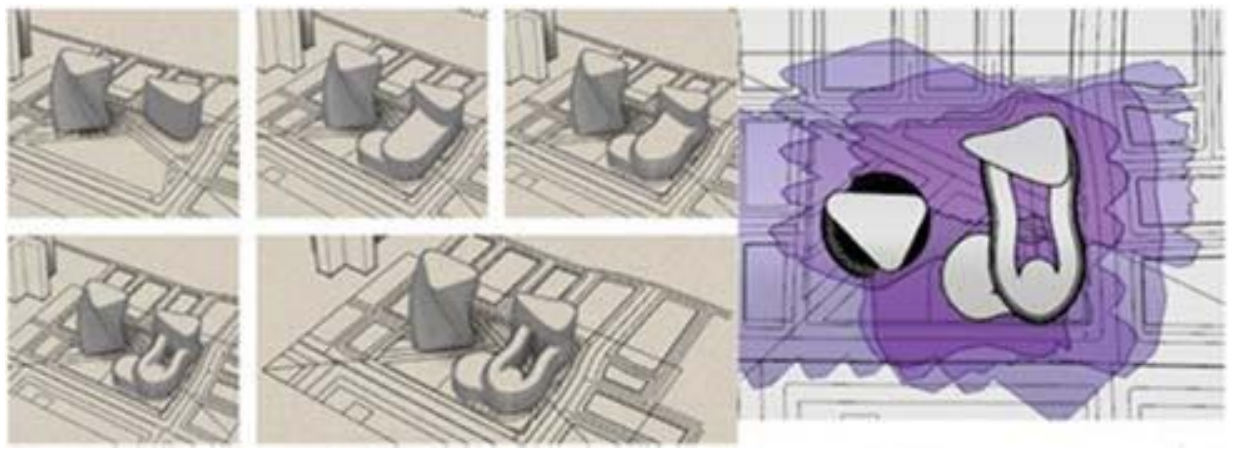

Fig. 22. Analysis of overshadowing area [4]

The mass is another aspect, was investigated in this study to obtain the optimum solution by reduce the heat gain, as the mass is considered as the landmark for the site. Parametric design was utilized in this building to decrease the solar heat gain by determining the rotation degree of the building, which influence on the aesthetic, structural forms, and the tilted wall which can influence on the interior spaces, see Fig. 23. The simulation concluded that; the influence of rotating the building $90^{\circ}$ will decrease the heat gain to $1.321,26 \mathrm{Wh} / \mathrm{m}^{2}$ which was the lowest value of heat gain.
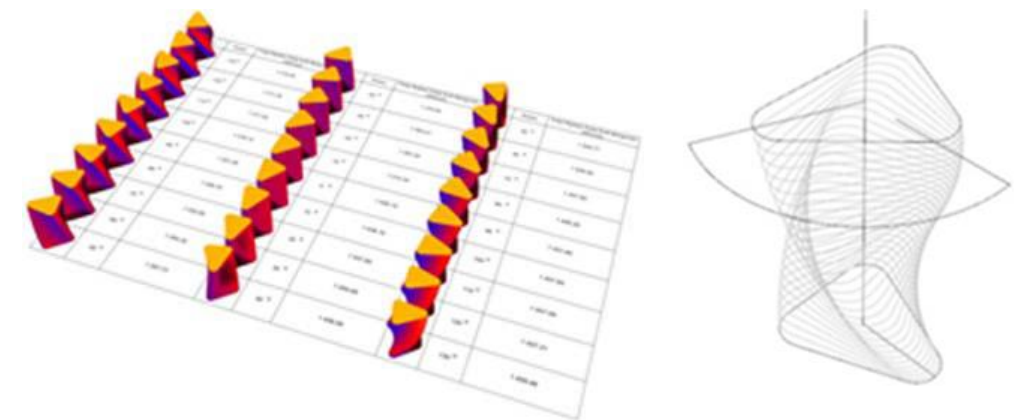

Fig. 23. Building mass study [4]. 
The study summarized that parametric approach is more practical than the conventional methods in terms of simultaneous coordinate and accountable.

According to morphological concept, Vasiliki and Odysseas [48] proposed a parametric residential building in Cyprus that designed based on the climatic and functional issue. The design method of the building depends on solar radiation and daylight in this location, and how parametric design could help to perform this design, and provide many design alternatives as a bioclimatic system [49]. The study aims to provide sufficient daylight in all building's spaces, and exploiting the solar energy for heating aspect. These climatic parameters will be connected parametrically, in order to manipulate with the units orientation to meet the environmental requirements. The model was conducted using Grasshopper as a parametric algorithmic software, the climatic analysis was done using Geco as an engine to Ecotect software which is used as an environmental software.

The study analysis proposes four solution for the residential building which can cover all possible bioclimatic requirements, putting in consideration the structure system, orientation and atheistic aspect, see Fig. 24.
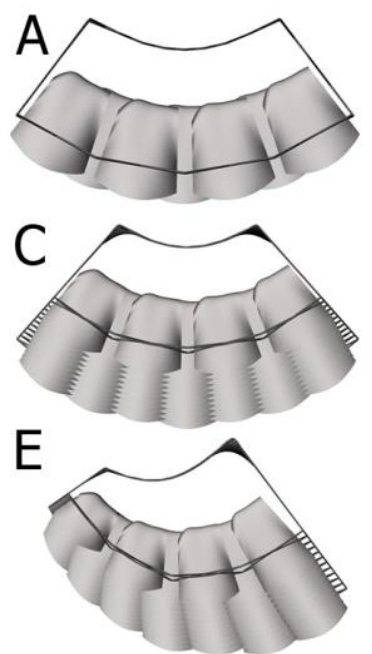

G

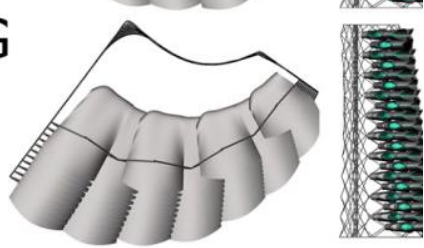

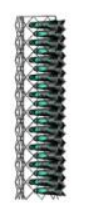
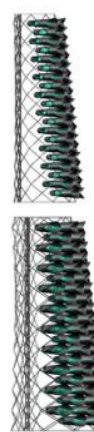
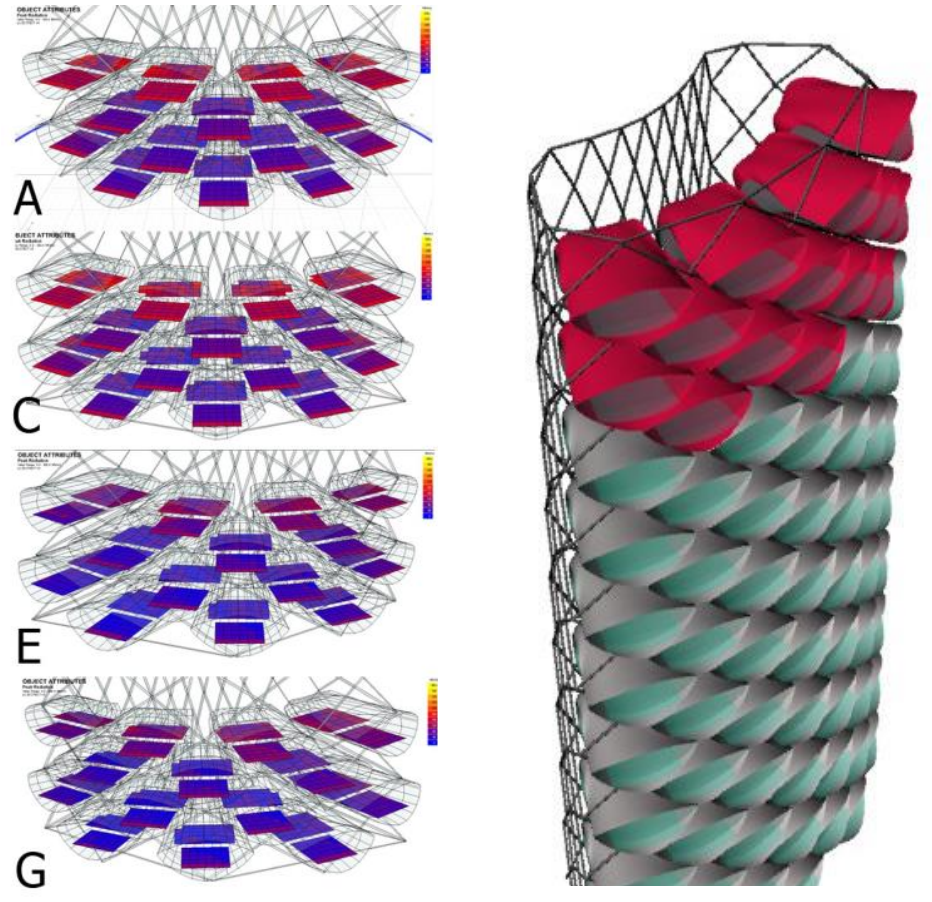

Fig. 24. The four solutions for the system's geometry, and the environmental analysis for each solution [48].

The study founded that lighting and solar energy can be reduced to a desirable results by adding extra canopy started with $3 \mathrm{~m}$ and ended with $1.5 \mathrm{~m}$ from east to west respectively. Moreover, the study recommended to add some bioclimatic elements including passive heating and cooling systems. The study concluded that the performance of daylight and ventilation levels can be improved by using parametric design approach, via changing the morphology parameters through bioclimatic analysis. Comparing to other buildings in the same area, the use of bioclimatic principals can enhance the quality of people's lives, regarding to morphological and functional aspects. 


\subsection{Fenestration design}

El Daly [50] investigated in fenestration allocation design to optimize daylight inside a multipurpose building in Cairo. He claims that conventional windows are now a debatable issue concerning to the environmental rating system (LEED) [51]. He used parametric design as a heuristic algorithms to be integrated with the LEED rating system in order to achieve the required daylight amounts with a minimum solar radiation inside the building. Hence, the design method depends on finding the suitable allocations for windows to comply with LEED requirements. The reason of using heuristic algorithm in this study, to solve the problems in limited steps, which try to find the optimum solution among all possible parameters.

The simulation of the building created in Grasshopper based on Rhinoceros, with the help of Geco plugin which transforming data to Ecotect to obtain the environmental analysis. Then the data optimization done with a tool called "Galapagos" and known as a genetic algorithm, which is the most common optimization algorithm used in parametric design, see Fig. 25.

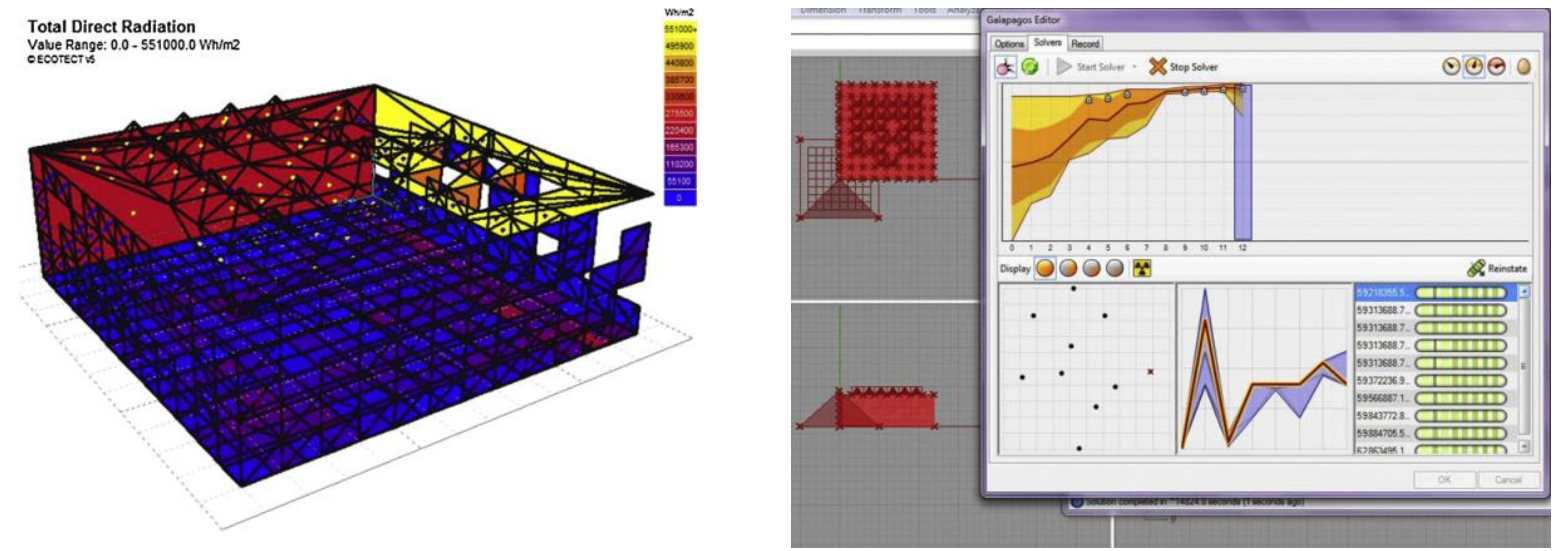

Fig. 25. Grid analysis by Ecotect (left), Galapagos interface (right) [50]

The use of optimization method in this study contributed to decrease total solar radiation loads to $26 \%$, which was lower than the total loads found in the initial parameters. Accordingly, the study summarized that the automation of fenestration allocation based on parametric design and regarding to LEED can be achieved using three main steps; the first by design the LEED requirements parametrically, the second step is the automatic selection of solutions through the integration between simulation program and heuristic algorithm, and the last one is choosing the optimum solution for the façade design.

For the same issue, Burak and Soofia [52] investigated in using generative algorithms to explore design alternatives for the fenestration system of a building in a hot climate territory in Cyprus. The study aimed to customize shading devices for the building which can optimize daylight, and reduce solar heat gain. The method of this study conducted by using Diva for Rhino for environmental analysis, Grasshopper as a parametric modelling tool, and Galapagos plugin to optimize the simulated results. The ambient bounces in the study was kept at 2 in Radiance parameters in order to speed the simulation process, on the other 
hand, this influence on the accuracy of the values of the DF. The study concluded that average DF was increased by $25 \%-67 \%$ in all alternatives. Accordingly, integrated parametric design software can improve the performance of the buildings, regarding to form and function aspects, moreover, provide several alternatives for the design in early stages.

Pil and Steffen [53] investigated in parametric method in Grasshopper to generate different fenestration systems for a room that fulfils performance criteria regarding indoor climate, daylight and energy saving, see Fig. 26. The method includes a new plugin in Grasshopper called ICEbear which can simulate annual indoor climate, daylight and energy performance of complex geometries based on hourly weather data. This tool is used simultaneously with Galapagos optimization algorithm in order to generate design solutions based on the designer conceptual idea. The aim of this method is to reach maximum energy used for the building operation ( $25 \mathrm{kWh} / \mathrm{m}^{2} /$ year) while fulfilling thermal class II without having more than 100 hours above $26 \mathrm{C}^{\circ}$, and minimum daylight autonomy of $60 \%$ in a point in the middle of the room.
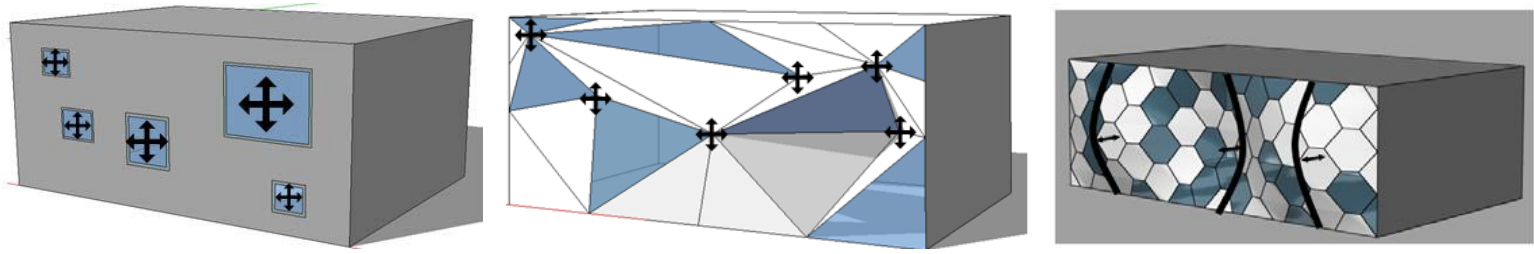

Fig. 26. Examples of parametric models concepts and variables [53].

The study concluded that the method can generate an almost optimum solution based on the designer concepts, which can achieve indoor environmental requirements.

\subsection{Windows design}

Ma and Hiroatsu [54] used parametric design in their study to optimize daylight and heat gain inside an office building in Beijing. The study method depends on finding the best size window area on each wall to minimize the energy consumption and maximize the useful daylight illuminance. The experiment done by creating the model in Grasshopper based on Rhinoceros, and the climatic simulation was done using Ladybug and Honeybee as an engines to EnergyPlus, Radiance and Daysim, in order to study the environmental state parametrically. Additionally, the study used Galapagos plugin to achieve the role of optimization, which provides a generic platform for the application of evolutionary algorithms to be used on a wide variety of problems by non-programmers. Moreover, Galapagos as mentioned previously can provide simple operation, fast speed of calculation results, and produces range of optimized solutions.

The study found that south oriented window is the best orientation, followed by north according to this selected territory, which aiming to minimize the annual total thermal energy. Whereas, heating energy in this location is needed more than cooling energy, furthermore, the study concluded that vertical window is the 
optimum solution in $63 \%$ of the time, with height $3.063 \mathrm{~m}$ and width $1.959 \mathrm{~m}$, in order to improve daylight illuminance to be greater than 300Lux, comparting to square and horizontal window with the same area. Generally, the study summarized that parametric design can optimize the selection of window design strategy concerning to illuminance and energy analysis, in order to minimize the annual total thermal energy and obtain the best orientation. In addition, the use of parametric technology in early design stage can improve the design quality and provide generation of practical global optimization and solution strategy for building design.

\subsection{Façades design}

Daylight optimization was investigated by Y. Elghazi, A. Wagdy, S. Mohamed and $A$. Hassan [55] using Kaleidocycle design technique in a residential façade in Cairo based on Origami, in order to enhance the daylighting in a living room and achieving the requirements of LEED V4 [56]. The methodology of this research was focusing on using the parameters of Kaleidocycle logic, which was conducted by applying parametric design based on Rhinoceros, Grasshopper and Diva; while Diva is an engine to Radiance and Daysim [57].

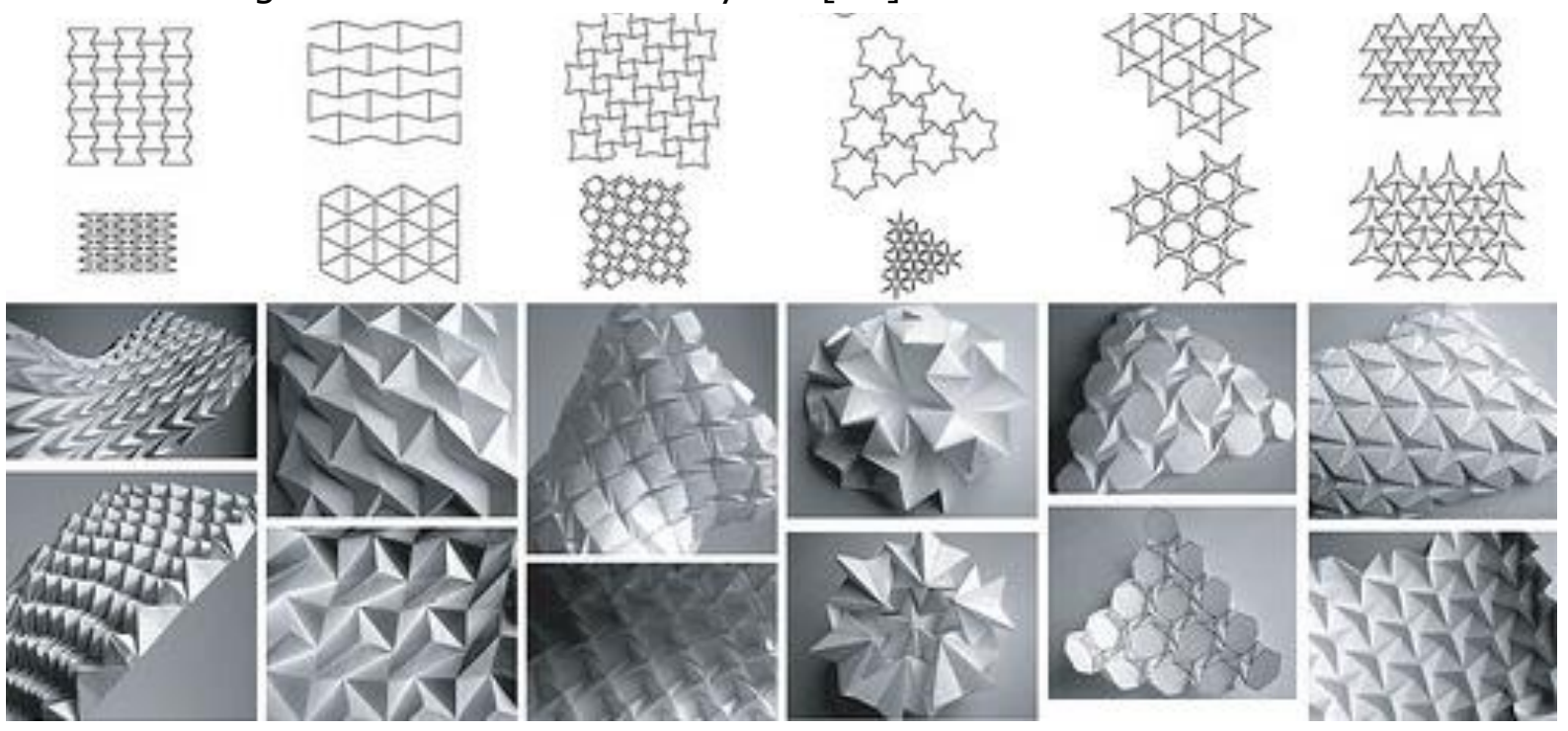

Fig. 27. Origami forms based on geometrical rules [55].

It can be observed in Fig. 27. that Origami is a folding paper techniques, which offers a finite set of paper shapes based on sequence and relationships between surface and points which can be defined by rules, moreover, it is a type of manual algorithm that can be translated into parametric shapes [58].

The façade concept in this study is formed as Kaleidocycle skin based on Origami technique. Kaleidocycle is defined as a rotating rings of tetrahedrons which are usually used with the mathematical exercises. Each tetrahedron in the cycle is linked to its predecessor and successor at opposite edges, where the movement technique treats each tetrahedron as an independent element [59]. 
The process of this research was done using genetic algorithm in order to optimize the results.

The results showed that Kaleidocycle rings with $30 \mathrm{~cm}$ size and $64^{\circ}$ rotation angle achieved $100 \%$ of daylight distribution which exceeded LEED v4 requirements (75\%) and accepted Daylight Availability standard. The research summarized that LEED V4 requirements can be achieved via using parametric techniques, in addition, the integration of daylight simulation tools and genetic algorithm contributes in achieving better daylight performance.

Another research in the same area investigated in using origami concept with parametric design, done by Avergauw, Lalegria, Kroovers and Niels [60]. The study concentrated in using an adoptive shading systems which can respond to the environmental circumstances. This system is based on curved-line folding technique which depends on kinematic behaviour. This technique provides wide opportunity to generate flexible shapes, which can be conducted by pushing specific endpoints in the geometrical shape using the small curved lines which can easily squeezed, as shown in Fig. 28. The significant character of this system that it can give higher displacement in its formation with low forces added to its vertices [61]. The model morphology was created and controlled parametrically using Grasshopper.
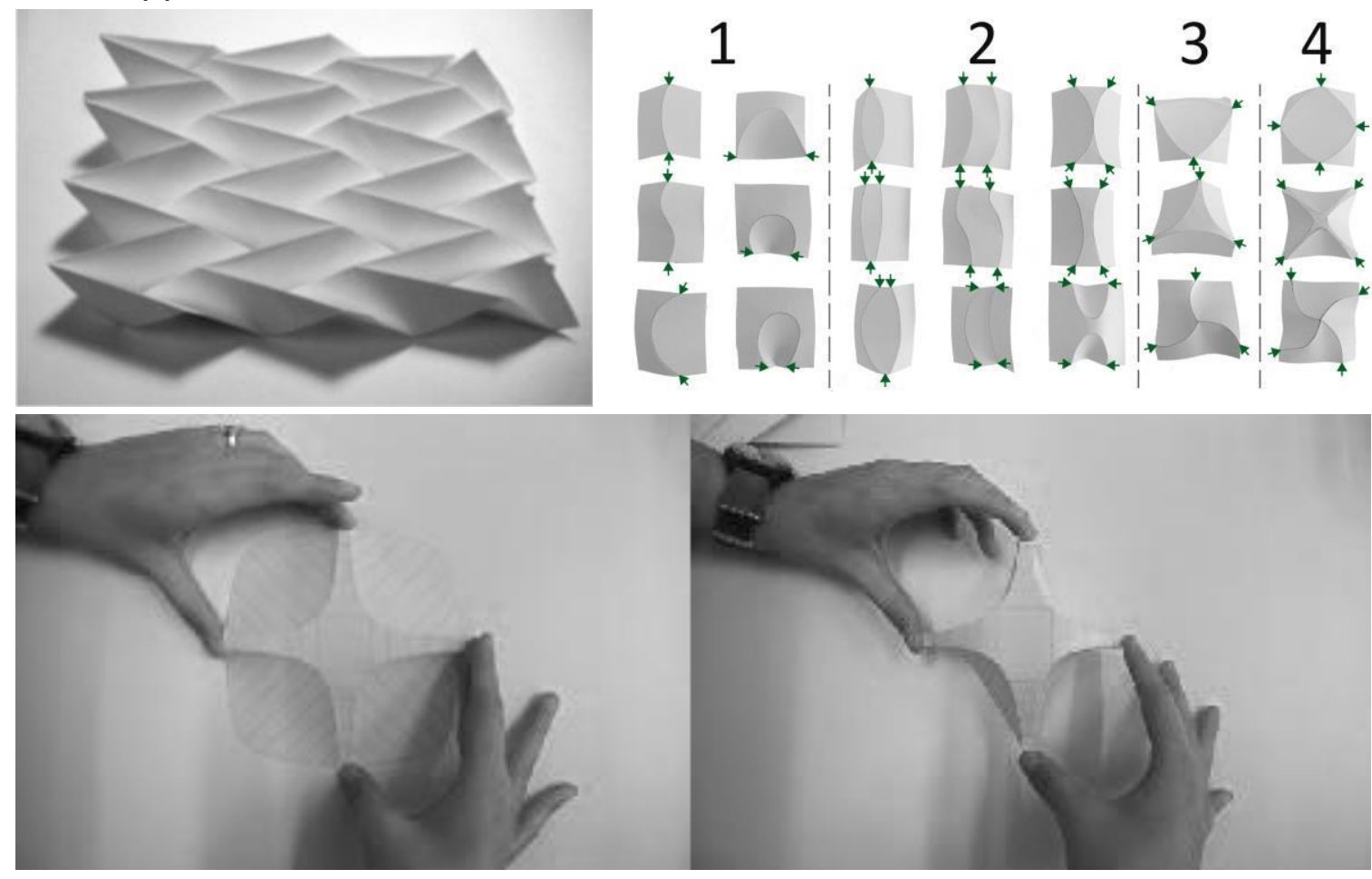

Fig. 28. The kinematic behaviour using the curved line adoptive [60].

The previous study aims to save energy consumed and enhance the indoor comfort, using the concept of kinematic behaviour based on parametric design. The study resulted that using adaptive shading parametrically can improve the daylight exploitation and energy saving. 
In Abu Dhabi, Aedas [62] developed "Al-Bahr Tawers" the two 25 story office towers which were parametrically designed, and inspired from an Islamic architectural element called "Mashrabiya", via using the tessellation of the hexagonal shape to create a mosaic scene in the façade, see Fig. 29.
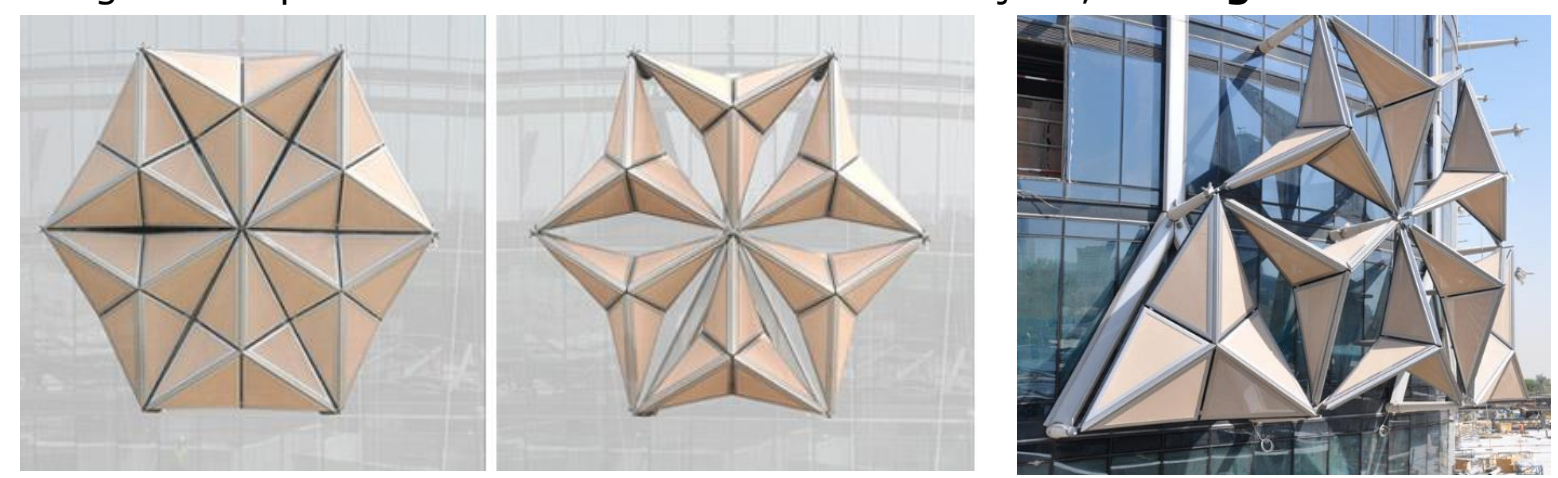

Fig. 29. Transformation of the hexagonal shape in the façade [62].

The façade consists of 1000 panels of connected triangular screens arranged in a series of scalable hexagonal shape, which are folding up to protect the façade form direct solar radiation. The hexagonal shape is responding automatically to the sun movement in an adaptive fitting system [63], to achieve better daylight performance and energy saving. The design succeeded to reduce heat gain and glare by $50 \%$, meanwhile, giving the Islamic atheistic shape. Moreover, the parametric façade, together with solar thermal panels for hot-water heating and photovoltaic panels on the roof, minimize the need of electrical lighting and cooling energy, and reduce the total carbon dioxide emissions by over 1750 tons per year.

Narangerel and Lee [64] investigated in the same area using south oriented 3D façade patterns to enhance daylight performance and reduce electricity consumption in Korea without any urban context. The process was done using parametric approach based on Grasshopper, Ladybug and Honeybee, see Fig. 30.

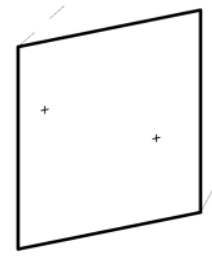

C. Additional points

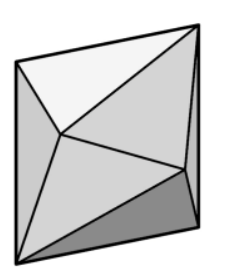

E. Applying materials

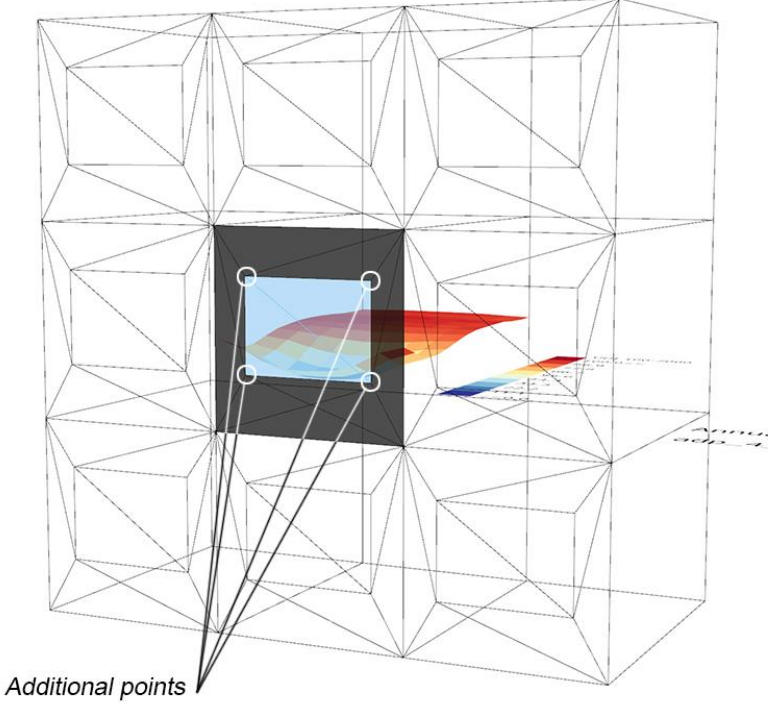

Additional points

Fig. 30. Façade geometry generation [64]. 
The model was created by increasing the points on the rectangular building façade units and connect them with the vertices' corner of the façade apertures. The method of this study suggested the optimal extrusion lengths at the given points and the combination of materials of the surfaces which were generated from the Delaunay triangulation by means of multi-objective optimization [41]. The suggested method in this research showed high flexibility and compatibility of generating any façade design using the proposed technique. The authors claimed that the method could be used effectively to create several design alternatives of an office building and to assess the daylighting performance according to a given location. The study summarized that facade models can save energy and enhance daylighting performances.

M. Gomaa and W. Jabi [65] investigated in complex facades using parametric tools (Autodesk Revit and 3D Max) in order to evaluate and compare the performance of daylighting analysis by using these two software. The experiment was done by making three types of model; using Revit, 3D Max and a physical scaled model. The physical scaled models were conducted by 3D printing and laser cutting processes, which was used as a reference case for comparison purposes. The initial test was done with as simple unglazed opening room. The next set of tests used three types of parametric patterns to form the façade geometries (see Fig. 31), which approximate some of the common used shapes in modern building envelopes. Daylighting analysis was performed using the available tools in each software. The assessment of results depends mainly on evaluating differences in illuminance values which reported form each software and then comparing them to the values of the physical model.
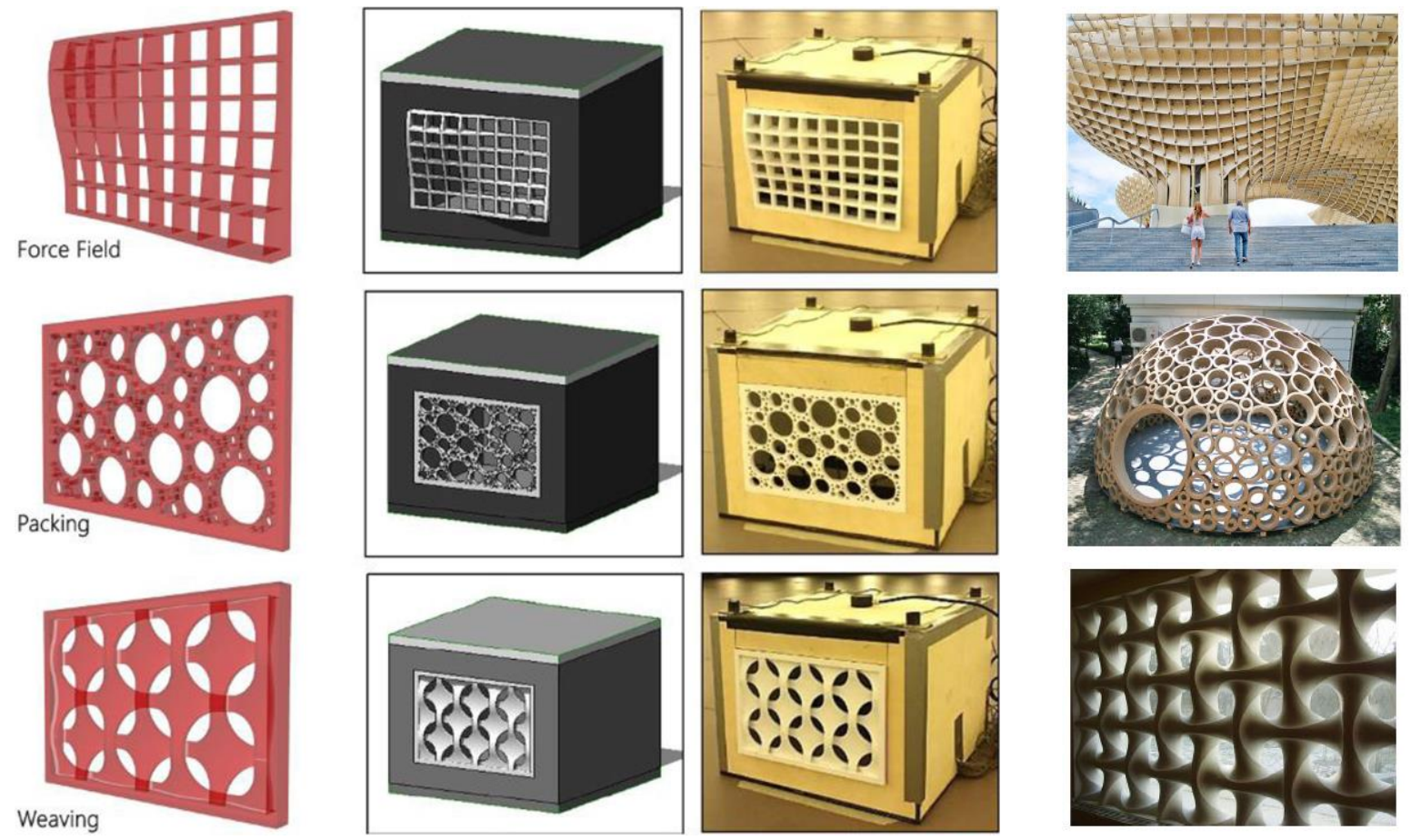

Fig. 31. The three chosen patterns in a three modeling types [65]. 
The study summarised that Rivet is better in using fast and simple geometries with daylight analysis when high levels of accuracy are not needed, however, in contrast with 3D Max, which consider to perform better with sophisticated geometries. Additionally, the rapid progress of parametric modelling which integrated with fabrication technologies, has made daylighting analysis of complex geometries less reasonable, comparing to the real model. Therefore, the existing daylight simulation tools need validations and crucial upgrades in order to control the increasing gap between predictions and physical reality.

In a similar research, Elliot and Christoph [66] used parametric design and energy simulation tools to determine the influence of daylight on façade's shading designs and the expected energy used in the building, cost optimization for the building and the amount of carbon emitted from the building. The study conducted by using Grasshopper for simulation modelling, EnergyPlus based on Diva for the environmental studies, and Galapagos for design optimization. The study summarized that the designer should put in consideration the climatic changes and how to deal with a physical parameters of a static building to match the environmental changes over the time. Accordingly, parametric design can anticipate varieties of scenarios for the building to get the optimized performance.

Mahmoud and Elghazi [67] investigated in kinetic facades [68, 69] using parametric design to optimize the daylight in a south oriented facade in Cairo. The façade consists of a moveable hexagonal pattern which is controlled using Grasshopper in order to study the daylight distribution inside the building, aiming to achieve the requirements of LEED v4. The study showed an improvement in daylight between $20-50 \%$ through the four seasons, comparing to traditional facades. The method of this study based on kinetic system, via controlling the rotation of hexagonal components in the façade as shown in Fig. 32.

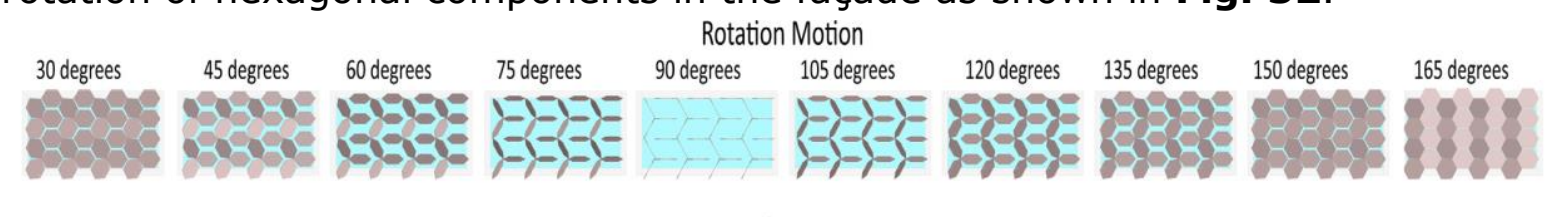

Translation Motion

$10 \%$ of the cell size $20 \%$ of the cell size $30 \%$ of the cell size $40 \%$ of the cell size $50 \%$ of the cell size $60 \%$ of the cell size $70 \%$ of the cell size $80 \%$ of the cell size $90 \%$ of the cell size $100 \%$ of the cell size री

Fig. 32. Patents of the rotation motion for the kinetic façade [67]

\subsection{Photovoltaics design}

Hend, Ayman, Paolo, Robert and John [70] investigated in the integration between photovoltaics technology and buildings' structure, while they are recommended renewable energy source. The main aim of this study is using parametric design with photovoltaics membrane structure, in order to solve complex relations within the membrane formation such as; the membrane's geometry, layout orientation, shadowing, analyse the daylight pattern on the 
membrane surface, calculate the stress distribution in different weather conditions and the maximum deflection allowed for the membrane surface under different loading conditions. The study argued that these former aspects can be integrated together parametrically, via using Grasshopper algorithms, while this parametric software can provide multiple facilities in a real time process for these complex aspects. The study summarized that parametric method can optimize many environmental aspects such as maximum daylighting absorption and energy saving, however, the study require more research to analyse more geometrical solutions with different structural parameters.

\subsection{Summary}

It can be noted from previous studies that parametric design has a significant influence on daylight performance and energy saving, especially for complex projects and innovative concepts, while it can provide quick iteration, real time results, data analysis, time saving, integrated relations and the optimization characteristic. The next table is summarising daylight performance and energy saved in some of the previous literatures through using parametric design.

Table 1. Daylight performance and energy saved within parametric design.

\begin{tabular}{|c|c|c|c|c|c|}
\hline Reference & $\begin{array}{c}\text { Type of } \\
\text { Daylighting } \\
\text { Design }\end{array}$ & $\begin{array}{c}\text { DF } \\
\text { Improvement }\end{array}$ & $\begin{array}{c}\text { sDA } \\
\text { Improvement }\end{array}$ & $\begin{array}{c}\text { Reduce } \\
\text { Solar Heat } \\
\text { Gain }\end{array}$ & $\begin{array}{l}\text { Energy } \\
\text { Saving }\end{array}$ \\
\hline [31] & Louvers design & & $100 \%$ & & \\
\hline [38] & $\begin{array}{c}\text { Automated } \\
\text { shading system }\end{array}$ & & & & $50 \%$ \\
\hline [40] & Skylight design & & & & $35 \%$ \\
\hline [43] & Skylight design & & & $30 \%$ & \\
\hline [50] & $\begin{array}{c}\text { Fenestration } \\
\text { design }\end{array}$ & & & & $26 \%$ \\
\hline [52] & $\begin{array}{l}\text { Fenestration } \\
\text { system }\end{array}$ & $67 \%$ & & & \\
\hline [53] & $\begin{array}{l}\text { Fenestration } \\
\text { system }\end{array}$ & & $60 \%$ & & \\
\hline [55] & Façade design & $100 \%$ & & & \\
\hline [62] & Façade design & & & $50 \%$ & \\
\hline
\end{tabular}

\section{Conclusions and outlook}

This paper has presented a literature review on the origin, principle, implementation and applications of parametric design concept in general, and specifically the relation between parametric design and daylighting research. The parametric design has been getting popular in the recent years to address the design complexity of modern buildings, by applying advanced modelling tool to refine the design parameters simultaneously. The parametric design has been 
used widely in the areas of architecture, structural design, urban planning, fashion design, etc., while its applications for daylighting research are still growing.

The most common software used for this aspect is Grasshopper based on Rhinoceros 3D as a parametric modelling approach. Grasshopper is developed to be connected to multiple plugins in order to facilitate the relation between different disciplines, with the same simulation approach. For daylighting simulation; Diva, Ladybug and Honeybee are used as plugins to generate a weather simulation and daylight analysis. These plugins are connected to Grasshopper and used as an engine to Ecotect, EnergyPlus, OpenStudio, Radiance and Daysim, in addition, to define the weather properties of a specific territory by using EPW file. The genetic algorithmic plugin "Galapagos" is used as an optimization tool to find the best solution.

The advantage character of this parametric software that it can control and amend all the design elements individually or integrated, and any modification or alteration in the ambient will influence on the whole model simultaneously. Therefore, the use of parametric design within daylight can improve the performance of buildings' design, daylighting and energy saving in the early stages of design.

Link with buildings' thermal performance simulation and visual comfort will be an attractive directions for parametric design in daylighting for future research.

\section{Acknowledgement}

Thanks to the Egyptian Government for their financial support for a full scholarship, and thanks to Helwan University in Egypt for their help and support to nominate me to this scholarship. 


\section{References}

1. Davis, D., A History of Parametric. Available at: $\mathrm{h}$ ttp://www. danieldavis. com/d/history, 2013.

2. Frazer, J., Parametric Computation: History and Future. Architectural Design, 2016. 86(2): p. 18-23.

3. Wang, J., J. Li, and X. Chen. Parametric design based on building information modeling for sustainable buildings. in Challenges in Environmental Science and Computer Engineering (CESCE), 2010 International Conference on. 2010. IEEE.

4. Hanan, I.I.H., et al., Parametric Approach as a Tool for Decision-making in Planning and Design Process. Case study: Office Tower in Kebayoran Lama. Procedia - Social and Behavioral Sciences, 2015. 184: p. 328-337.

5. Gerber, D.J., Parametric practices: models for design exploration in architecture. 2007: Harvard University.

6. de Ruiter, M.M., Advances in computer graphics III. 1988: Springer Science \& Business Media.

7. Reddy, E.J., C. Sridhar, and V.P. Rangadu, Knowledge Based Engineering: Notion, Approaches and Future Trends. American Journal of Intelligent Systems, 2015. 5(1): p. 1-17.

8. Ahamed, S.N., J.V. Kumar, and P. Sravani, Weight Optimization Of Empennage Of Light Weight Aircraft. International Journal of Technology Enhancements and Emerging Engineering Research, 2014. 3(4): p. 40-57.

9. Hillyard, R.C. and I.C. Braid, Analysis of dimensions and tolerances in computer-aided mechanical design. Computer-Aided Design, 1978. 10(3): p. 161-166.

10. Moretti, L., F. Bucci, and M. Mulazzani, Luigi Moretti: opere e scritti. 2000: Electa.

11. Davis, D., Modelled on software engineering: Flexible parametric models in the practice of architecture. 2013, RMIT University.

12. Dana, J.D., On the drawing of figures of crystals. 1888: publisher not identified.

13. Monedero, J., Parametric design: a review and some experiences. Automation in Construction, 2000. 9(4): p. 369-377.

14. Rogler, K., Energy Modeling and Implementation of Complex Building Systems. 2014.

15. Yu, X. and Y. Su, Daylight availability assessment and its potential energy saving estimation A literature review. Renewable and Sustainable Energy Reviews, 2015. 52: p. 494-503.

16. Lagios, K., J. Niemasz, and C.F. Reinhart, Animated building performance simulation (abps)linking rhinoceros/grasshopper with radiance/daysim. Proceedings of SimBuild, 2010.

17. Erlendsson, Ö., Daylight Optimization-A Parametric Study of Atrium Design: Early Stage Design Guidelines of Atria for Optimization of Daylight Autonomy. 2014.

18. Pratt, K.B. and D.E. Bosworth. A method for the design and analysis of parametric building energy models. in Proceedings of Building Simulation 2011: 12th Conference of International Building Performance Association, Sydney, Australia. 2011.

19. Saleh, M.M. and K.S. Al-Hagla. Parametric Urban Comfort Envelope An Approach toward a Responsive Sustainable Urban Morphology. in Proceedings of World Academy of Science, Engineering and Technology. 2012. World Academy of Science, Engineering and Technology (WASET).

20. Hudson, R., Strategies for parametric design in architecture: an application of practice led research. 2010, University of Bath.

21. Zarei, Y., The Challenges of Parametric Design in Architecture Today: Mapping the Design Practice. 2012.

22. pinterest. [cited 2016 19/12/2016]; Available from: https://www.pinterest.com/source/grasshopper3d.com.

23. Ali, M. 20122016 [cited 2016 19/12/2016]; Available from: http://www.grasshopper3d.com/photo/dsc-0158?context=latest.

24. Levin, G. Interactive Art \& Computational Design. 2015 24/3/2015 [cited 2016 19/12/2016]; Available from: http://golancourses.net/2015/jackkoo/03/24/looking-outward-6/. 
25. Sood, G. Biomimicry shoe that mimics bird's cranium is created using 3D printing. 20122016 [cited 2016 19/12/2016]; Available from: http://www.atcrux.com/2012/07/20/3534/biomimicry-shoe-that-mimics-birds-cranium-iscreated-using-3d-printing.html.

26. arch20. Shoes - Tea Petrovic. 2015 [cited 2016 19/12/2016]; Available from: http://www.arch2o.com/shoes-tea-petrovic/.

27. Davidson, S. Grasshopper. Sonic 2016 [cited 2016 29/7/2016]; Available from: http://www.grasshopper3d.com/group/sonic.

28. Pinterest. 20092016 [cited 2016; Available from: https://www.pinterest.com/milleychin/grasshopper_kangaroo/.

29. inhabitat. Twisted ContemPLAY Pavilion. 2012 [cited 2016; Available from: http://inhabitat.com/mcgill-university-students-build-twisted-contemplay-pavilion-out-oflocally-sourced-materials/contemplay-pavilion-1/.

30. Boake, T.M., Diagrid Structures: Systems, Connections, Details. 2014: Birkhäuser.

31. Wagdy, A. and F. Fathy, A parametric approach for achieving optimum daylighting performance through solar screens in desert climates. Journal of Building Engineering, 2015. 3: p. 155-170.

32. Banihashemi, S., et al., Climatic, parametric and non-parametric analysis of energy performance of double-glazed windows in different climates. International Journal of Sustainable Built Environment, 2015. 4(2): p. 307-322.

33. Henriques, G.C., J.P. Duarte, and V. Leal, Strategies to control daylight in a responsive skylight system. Automation in Construction, 2012. 28: p. 91-105.

34. Larson, G.W. and R. Shakespeare, Rendering With Radiance: The Art And Science Of Lighting Visualization. 2004: Booksurge Llc.

35. El-Sheikh, M. and D. Gerber. Building Skin Intelligence. in Proceedings of ACADIA. 2011.

36. Sjarifudin, F.U. and L. Justina. Daylight Adaptive Shading Using Parametric Camshaft Mechanism for SOHO in Jakarta. in EPJ Web of Conferences. 2014. EDP Sciences.

37. Choi, J., et al., Parametric Louver Design System Based On Direct Solar Radiation Control Performance. Journal of Asian Architecture and Building Engineering, 2014. 13(1): p. 57-62.

38. Konstantoglou, M. and A. Tsangrassoulis, Dynamic operation of daylighting and shading systems: A literature review. Renewable and Sustainable Energy Reviews, 2016. 60: p. 268283.

39. Henriques, G.C., TetraScript: A Responsive Pavilion, From Generative Design to Automation. International Journal of Architectural Computing, 2012. 10(1): p. 87-104.

40. Turrin, M., et al., Performative skins for passive climatic comfort: A parametric design process. Automation in Construction, 2012. 22: p. 36-50.

41. Turrin, M., P. von Buelow, and R. Stouffs, Design explorations of performance driven geometry in architectural design using parametric modeling and genetic algorithms. Advanced Engineering Informatics, 2011. 25(4): p. 656-675.

42. Nicol, F. and S. Roaf, Progress on passive cooling: adaptive thermal comfort and passive architecture. Advances in Passive Cooling, Earthscan, London, UK, 2007: p. 1-29.

43. Turrin, M., et al., Integrated design of a large span roof: a parametric investigation on structural morphology, thermal comfort and daylight. Proceedings of ICCCBE, 2010.

44. Cunningham, P., Zaferiou, P. \& Lagios, Kera, A Case Study in Reflective Daylighting. Perkins+Will Research Journal, 2014. Vol. 6, No. 1, pp 30-53.

45. Park, J.J. and B. Dave. Bio-inspired Parametric Design of Adaptive Stadium Facades. in Australasian Journal of Construction Economics and Building Conference Series. 2014.

46. Land, M.F., Eyes with mirror optics. Journal of Optics A: Pure and Applied Optics, 2000. 2(6): p. R44.

47. Land, M.F., Superposition images are formed by reflection in the eyes of some oceanic decapod Crustacea. 1976. 
48. Sarvani, V. and O. Kontovourkis, Parametric Design of a High-Rise Habitation Unit System through Lighting and Solar Energy Performances. Journal of Sustainable Architecture and Civil Engineering, 2013. 3(4): p. 9-18.

49. Chronis, A. and K.A. Liapi. Parametric Approach to the Bioclimatic Design of a Student Housing Building in Patras, Greece. in Proceedings of the eCAADe 2010 Conference. 2010.

50. El Daly, H.M.T., Automated fenestration allocation as complying with LEED rating system. Alexandria Engineering Journal, 2014. 53(4): p. 883-890.

51. USGBC, L., for New Construction and Major Renovations. US Green Building Council, Version, 2009. 2: p. 24-28.

52. Ercan, B. and S.T. Elias-Ozkan, Performance-based parametric design explorations: A method for generating appropriate building components. Design Studies, 2015. 38: p. 33-53.

53. Lauridsen, P.K.B. and S. Petersen. Integrating Indoor Climate, Daylight and Energy Simulations in Parametric Models and Performance-Based Design. in Proceedings of the Third International Workshop on Design in Civil and Environmental Engineering. 2014.

54. Qingsong, M. and H. Fukuda, Parametric Office Building for Daylight and Energy Analysis in the Early Design Stages. Procedia - Social and Behavioral Sciences, 2016. 216: p. 818-828.

55. Elghazi, Y., et al. Daylighting driven design: optimizing kaleidocycle facade for hot arid climate. in Aachen: Fifth German-Austrian IBPSA Conference, RWTH Aachen University. 2014.

56. USGBC, L., Reference Guide for Building Design and Construction v4. US Green Building Council, 2014.

57. Ward, G.J. The RADIANCE lighting simulation and rendering system. in Proceedings of the 21st annual conference on Computer graphics and interactive techniques. 1994. ACM.

58. Gao, W. and K. Ramani, Kaleidogami ${ }^{\text {TM}: ~ M u l t i-P r i m i t i v e ~ R e c o n f i g u r a b l e ~ A r t i s t i c ~ S t r u c t u r e s . ~}$ School of Mechanical Engineering School, Electrical and Computer Engineering, Purdue University: by Courtesy.

59. Fowler, P. and S. Guest. A symmetry analysis of mechanisms in rotating rings of tetrahedra. in Proceedings of the Royal Society of London A: Mathematical, Physical and Engineering Sciences. 2005. The Royal Society.

60. Vergauwen, A., et al. Parametric design of adaptive shading elements based on Curved-line Folding. in Proceedings of the First Conference Transformables 2013. 2013.

61. Schleicher, S., et al. Adaptive façade shading systems inspired by natural elastic kinematics. in Proceedings of the International Conference on Adaptive Architecture. 2011.

62. Aedas. Al Bahr Towers in Abu Dhabi. 20122016 [cited 2016 20/12/2016]; Available from: http://www.designboom.com/architecture/aedas-al-bahar-towers/.

63. Drozdowski, Z. and S. Gupta. Adaptive fritting as case exploration for adaptivity in architecture. in ACADIA 09: reForm ()-Building a Better Tomorrow [Proceedings of the 29th Annual Conference of the Association for Computer Aided Design in Architecture (ACADIA). 2009.

64. Narangerel, A., J.-H. Lee, and R. Stouffs, Daylighting Based Parametric Design Exploration of 3D Facade Patterns.

65. Mohamed Gomaa, W.J., Evaluating Daylighting Analysis of Complex Parametric Facades, in eCAADe. 2016.

66. Glassman, E.J. and C. Reinhart, FACADE OPTIMIZATION USING PARAMETRIC DESIGN AND FUTURE CLIMATE SCENARIOS.

67. Mahmoud, A.H.A. and Y. Elghazi, Parametric-based designs for kinetic facades to optimize daylight performance: Comparing rotation and translation kinetic motion for hexagonal facade patterns. Solar Energy, 2016. 126: p. 111-127.

68. Ramzy, N. and H. Fayed, Kinetic systems in architecture: New approach for environmental control systems and context-sensitive buildings. Sustainable Cities and Society, 2011. 1(3): p. 170-177. 
69. Barozzi, M., et al., The Sustainability of Adaptive Envelopes: Developments of Kinetic Architecture. Procedia Engineering, 2016. 155: p. 275-284.

70. Ibrahim, H., et al., Applicability of flexible photovoltaic modules onto membrane structures using grasshopper integrative model. Procedia Engineering, 2016. 155: p. 379-387. 